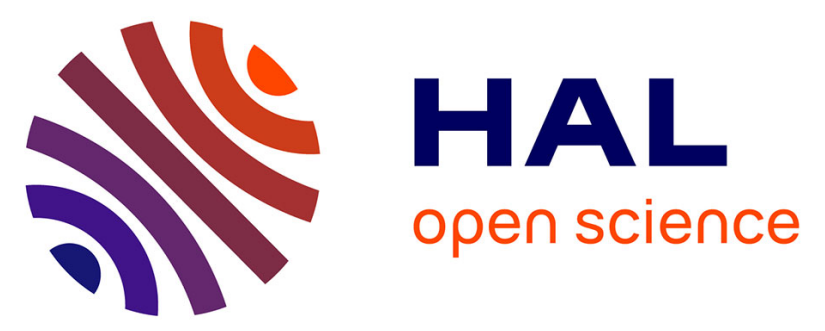

\title{
Comparison of three different adhesive joints using static and dynamic impact tests: development of a new drop weight impact test rig incorporating a modified Arcan fixture
}

\author{
Aurelien Maurel-Pantel, M. Voisin, F. Mazerolle, F. Lebon
}

\section{To cite this version:}

Aurelien Maurel-Pantel, M. Voisin, F. Mazerolle, F. Lebon. Comparison of three different adhesive joints using static and dynamic impact tests: development of a new drop weight impact test rig incorporating a modified Arcan fixture. International Journal of Adhesion and Adhesives, 2022, pp.103104. 10.1016/j.ijadhadh.2022.103104 . hal-03524358

\section{HAL Id: hal-03524358 \\ https://hal.science/hal-03524358}

Submitted on 13 Jan 2022

HAL is a multi-disciplinary open access archive for the deposit and dissemination of scientific research documents, whether they are published or not. The documents may come from teaching and research institutions in France or abroad, or from public or private research centers.
L'archive ouverte pluridisciplinaire HAL, est destinée au dépôt et à la diffusion de documents scientifiques de niveau recherche, publiés ou non, émanant des établissements d'enseignement et de recherche français ou étrangers, des laboratoires publics ou privés. 


\title{
Comparison of three different adhesive joints using static and dynamic impact tests: development of a new drop weight impact test rig incorporating a modified Arcan fixture
}

\author{
A.Maurel-Pantel*, M.Voisin, F.Mazerolle, F.Lebon \\ Aix Marseille Univ, CNRS, Centrale Marseille, LMA, Marseille, France
}

\begin{abstract}
The paper proposes to compare static and dynamic properties of three structural adhesives selected for the integration of optical space systems. These comparisons are based on an original methodology using static test and drop weight impact test to determine the best shock-strength candidate. In a first section, the design of the drop weight impact rig integrating a modified Arcan fixture is described. Then validity of the impact test rig is discussed on a simplified case thanks to an analytical model of "soft impact" available in literature. In a second section, static tests results are presented and the adhesive's critical stresses are identified with a point stress criterion. Finally, impact tests results are used to discuss the dynamic tensile and shear behaviour of each adhesive with different stress concentrations. Static critical stresses and impact strengths of the adhesives are reported. In conclusion a strategy of adhesive choice is discussed.
\end{abstract}

\footnotetext{
* Corresponding author

Email address: maurel@lma.cnrs-mrs.fr (A.Maurel-Pantel)
} 
Keywords: Adhesive joint, Impact tensile load, Impact shear load, Arcan fixture, Free edge effect

1

2

\section{Introduction}

Over the last 20 years, structural adhesives have been increasingly integrated into complex structures in order to reduce mass, particularly in the field of transport and civil engineering. Choosing the optimal adhesive forces us to make a decision on a multi-factorial trade-off. Indeed, weight must be reduced but neither sacrificing structural performance and nor creating new zones of vulnerability.

It is essential to carry out experimental tests to characterise the mechanical performance of adhesives. Static tests are well documented in the literature. In the last few years, the interest for the dynamic behaviour characterisation has been growing. Recently, a review of adhesives and adhesive joints under impact loading was published by Machado et al. [1]. Authors described that the adhesive joints behaviour under impact is complex and influenced by the properties of the adhesive, the joint geometry and the loading modes. You et al. [2] proposed a review of experimental techniques to determine impact properties of adhesive bonds.

To characterize impact strength, a dynamic loading have to be imposed on the specimen. Two main types of dynamic loading are considered: the first one is an "high speed loading" of the specimen in a tensile test machine at a high strain rate driven by a servo hydraulic systems as in Blackman [3]; the second one is a "shock elastic wave type": the impact on the sample can be direct or indirect, and corresponds to Izod and Charpy pendulums, 
drop weight tower as in Beevers and Ellis [4], powder and gas gun, and split Hopkinson bar (SHPB) techniques. These experimental methods are detailed in Goglio [5], and da Silva [6].

Within framework of work carried out on direct bonding process for optical space systems design $[7,8,9]$, we need to characterize three adhesives via both static and dynamic tests in order to compare the identified properties and to find the best candidate. The chosen adhesive will be finally to integrate direct bonded optical space systems that are subjected to high dynamic loading in the launcher and static loading during preparation on the ground.

The paper describes the development of a drop weight impact rig integrating a modified Arcan fixture to compare mechanical properties of three selected structural adhesives. These comparisons are based on static and drop weight impact test results obtained for different loading modes and stress concentrations. As discussed by Adams and Harris in [10] about the critical assessment of the ASTM D950, we propose a new "energy" oriented methodology interesting for comparative studies.

In a preliminary section, the static test design based on a new modified Arcan fixture (cylindrical samples) and a new impact test rig are described. Then the validity (i.e good physical behaviour) of the impact test rig is discussed on a simplified case (an elementary sample whithout adhesive) thanks to an analytical model of "soft impact" available in the literature. As proposed by Vales et al. in $[11,12]$, we have developed a test rig based on the drop weight system of Beevers and Ellis [4] coupled with a modified Arcan fixture. Based on the work of Arcan et al. [13], the geometry of Arcan 
fixture allows us to test adhesive joints in a tensile machine with different loading directions. Moreover, based on the work of Cognard et al. [14], a set of different specimen geometries allows us to investigate stress singularities (well known as "edge effects") in the adhesive.

In a first section a short introduction describe the three selected adhesives and the adhesively-bonded specimens. In a second section, static test results are presented and adhesive's critical stresses are identified with a point stress criterion. Finally, the impact tests results are the starting point to discuss the dynamic behaviour of the three adhesives in traction and shear with different stress concentrations. The adhesive's mechanical strengths in static and dynamic are compared using two characteristic experimental values: the static critical stress and the impact strength. In conclusion a strategy of adhesive choice is discussed. 


\section{Preliminary work: design and validation of static and impact test rigs}

\subsection{Static test with a modified Arcan fixture}

Static tests are performed using a modified Arcan fixture [14]. This device consists in loading an adhesively-bonded assembly along a controlled axis which forms an angle with the axis sample between $0^{\circ}$ and $90^{\circ}$. It allows to apply a load in various orientations which results in a combined tensionshear load mode of the bonded joint. It is constituted of two half discs with several attachment points along the perimeter. These attachment points allow setting up the device on a standard tensile testing machine. For these investigations, the Arcan system is adapted to use cylindrical specimens. Positioning and holding of the test sample are carried out using flanges. These flanges fix the sample with screws uniformly distributed on its periphery (Fig.1). The flanges are made in 7075 Aluminum. The half-discs are made in 40CMD8S Steel in order to increase the system stiffness without adding too much mass. The flanges and interface with half-discs are pre-tensioned with M4 screws of class 12.9 with a controlled tightening torque of $4 \mathrm{~N} . \mathrm{m}$. The torque is controlled in order to ensure the same clamping condition during the experiments. Static tests are carried out on a tensile test machine, an electro-magnetic Instron (Fig.2(a)). The Arcan device is connected to the machine with a ball joint that guarantees isostatism and auto-alignment of the applied force. Tests were performed at a quasi-static speed of 0.5 $m m \cdot m_{i n}^{-1}$. The load is measured with a sensor with a capacity of $50 \mathrm{kN}$. Fig.2(b) describes the load displacement curves tested in traction and obtained for five rounded edge samples bonded with Cyanoacrylate adhesive. 


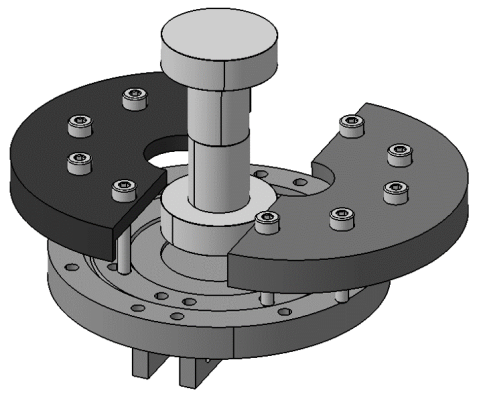

Figure 1: Homogeneous clamping device for the test samples.

86 We are able to identify the critical load at fracture (i.e first load drop on the curve).

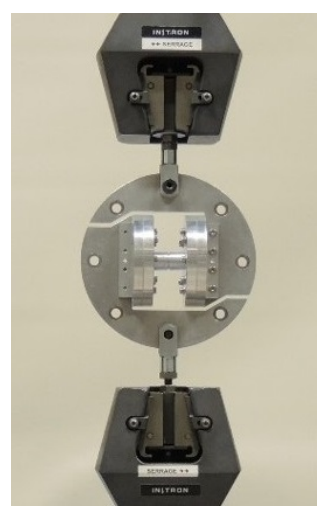

(a) Static test

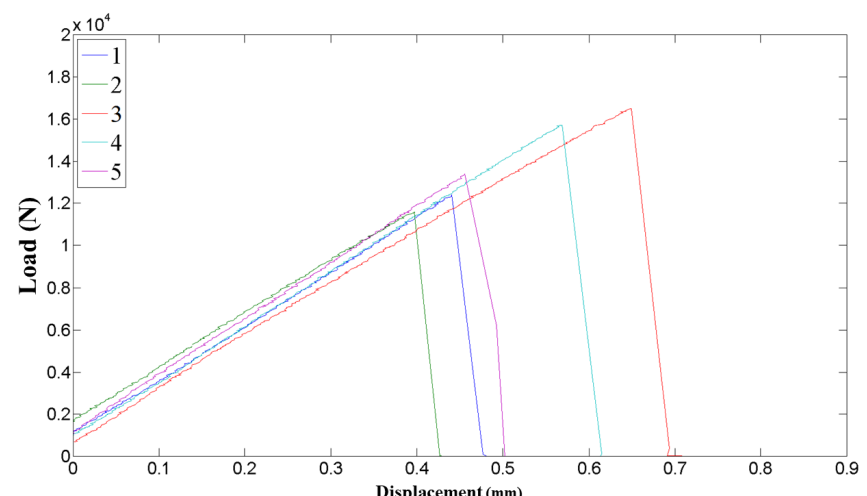

(b) load-displacement curves

Figure 2: (a) Description of the Arcan fixture mounted in the Instron tensile machine. (b) The load displacement curves tested in traction and obtained for five rounded edge samples bonded with Cyanoacrylate adhesive.

\subsection{Impact test machine with Arcan fixture}

The impact test machine is designed to generate a shock for different loading modes (traction, shear and mixed-mode) on the specimen. In order 
to respect these requirements, as described in Fig.3, the impact test rig is based on two principles the Beevers and Ellis drop weight test machine [4] and the modified Arcan fixture proposed. Beevers and Ellis machine imposes a tension load on a specimen by falling a weight along a tube connected to the specimen. They performed single lap shear tests on an adhesive joint. We propose to adapt their drop weight system and to integrate our modified Arcan fixture in order to be able to impact adhesively-bonded assemblies with different loading mode.

\subsubsection{Test machine design}

The new impact test bench including the Arcan fixture is detailed in Fig.3. The drop weight system is chosen to generate shocks. The steel impactor (noted (10) in Fig.3) is maintained through two electromagnets (9). When experimental test begins, the impactor slides along the bar until to its stop position against the impact zone (2). The specimen (7) is loaded in traction through the bar and the Arcan device. In order to ensure isostatism and to avoid plastic strain in the holes, the Arcan system is mounted between two pivot links (6) using pins and steel inserts placed on the half-discs. On the upper part, a ball joint (4) is added between the load sensor (3) and the pivot link (6) to ensure the alignment of the system in the direction of loading. A guidance system using calibrated bars and ball bushings (8) is used to avoid any rotation of the system during impact. The removable profile (1) allows to adjust the height of fall of the impactor up to $1 \mathrm{~m}$. The mass of the impactor is also a controlled parameter: steel impactors from $0.1 \mathrm{~kg}$ to $1.6 \mathrm{~kg}$ are used. In shear, we choose to limit the drop height to $0.5 \mathrm{~m}$ in order to not exceed a load threshold that could damage the Arcan 

data acquisition.

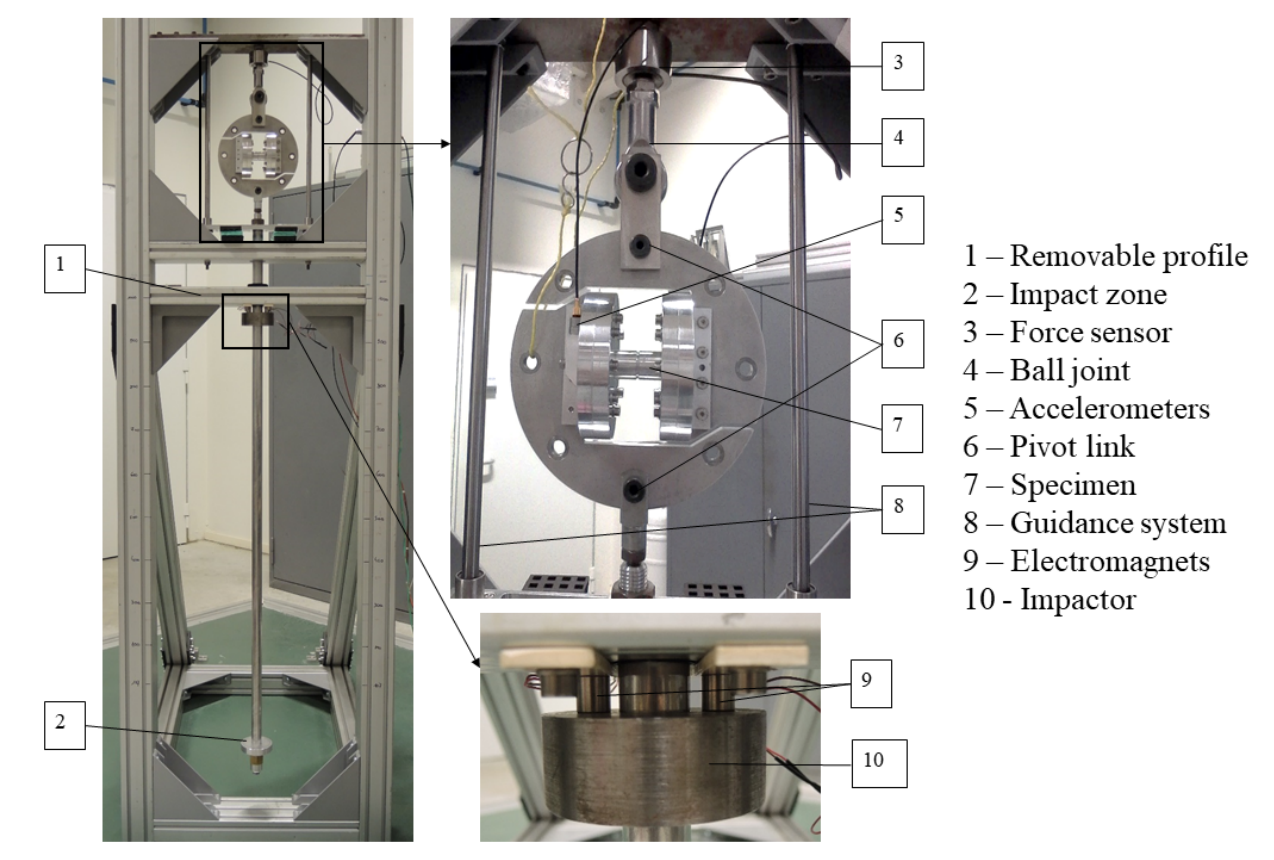

Figure 3: Drop weigh test machine incorporating a modified Arcan device

fixture (plastic strain in the radius of the angle). The system is equipped with a load sensor U9C/50kN from HBM, with a maximal capacity of $50 \mathrm{kN}$ and two accelerometers of Brüel Kjaer with a maximal capacity of 20,000 g. A PCI Express card with a sampling at $1 \mathrm{MHz}$ is used for high frequency

We used unidirectional accelerometers specifically chosen for impact tests. For the mounting of the accelerometers, two aluminum supports have been manufactured, they are screwed on the sample support of each half-disc (Fig.4(a)). These supports allow the accelerometer to be screwed in direction of solicitation. Fig.4(b) illustrates the mounting for the mode I (pure tensile testing), Fig. 4(c) for the mode II (pure shear testing) and Fig. 4(d) for the mixed mode. Accelerometers measurements allow us to validate that the 


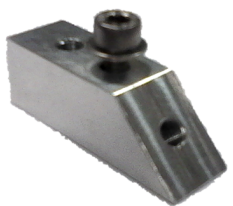

(a) Accelerometer support

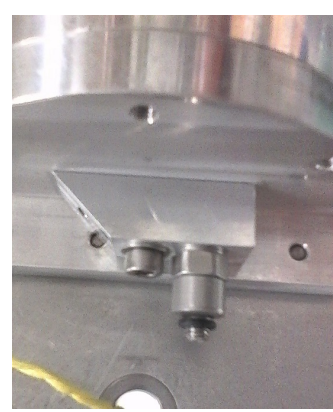

(b) Accelerometer in tensile configuration

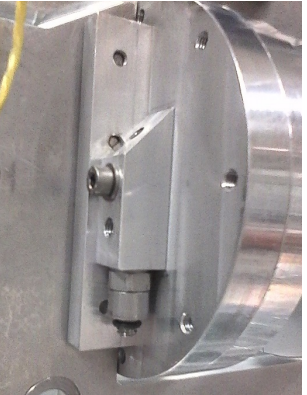

(c) Accelerometer in shear configuration

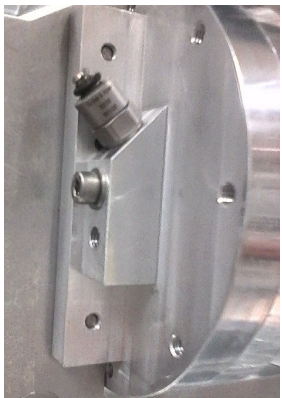

(d) Accelerometer in mixed mode configuration

Figure 4: Aluminum parts to support accelerometers in different configuration.

\subsubsection{Validation tests in a simplified case: one-piece specimens}

In order to validate the behaviour of our impact test machine, we decided to test a one piece specimen in traction and shearing. The protocol consists in checking the response of the impact test rig on a simplified case (i.e. an elastic material without the interface and interphase of the adhesive joint). The evolution of the maximal load seen by the specimen at different shock levels is experimentally observed by varying the drop height and mass of the impactor.

Our modified Arcan device is composed of different parts placed between the impactor and the load cell. We have controlled the successive assembly procedures to be sure to have a good reproducibility in experimental results. For instance, the tightening torque are controlled to not disturb the shock wave travel in the system. In traction, ten masses from $0.1 \mathrm{~kg}$ to $1 \mathrm{~kg}$ are 


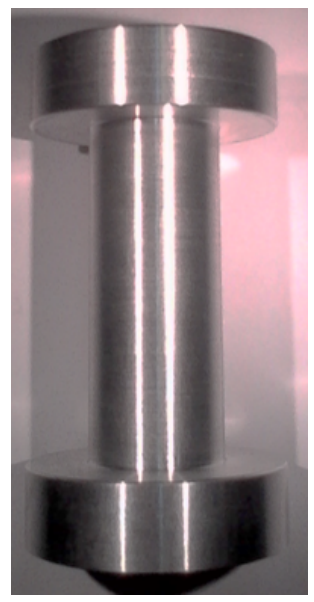

Figure 5: One-piece specimen without the adhesive joint.

released from 10 different heights from $0.1 \mathrm{~m}$ to $1 \mathrm{~m}$. In shearing, ten masses are tested but only up to a height of $0.5 \mathrm{~m}$ in order to avoid damage to the Arcan fixture. For each condition (mass, height), the impact is performed 3 times in order to validate its reproductibility and to quantify its dispersion. The maximal load underwent by the sample is recorded using the load cell acquisition during impact with a sampling at $1 \mathrm{MHz}$. Fig.6 describes the load curves measured for three impact tests performed for a drop of $0.9 \mathrm{~m}$ and a mass of $0.9 \mathrm{~kg}$ in traction. Considering these three tests, the tensile force curves are very similar. Finally the maximal positive value of forces are identified and compared with a theoretical shock model available in literature.

\subsubsection{Comparison with Brossard model}

We propose to confront our experimental results with the model proposed by Brossard [15]. Within the framework of this model, a soft impact is considered (i.e. where the materials deform elastically during the impact). 


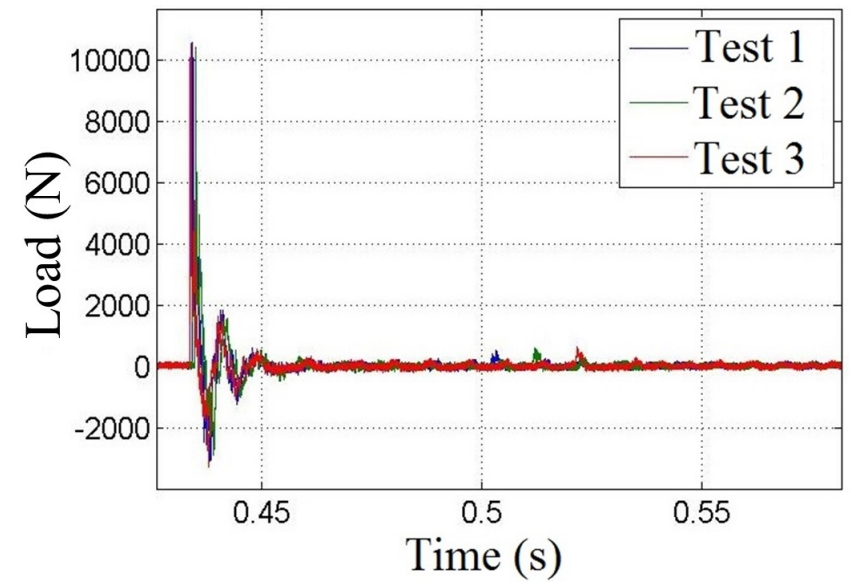

Figure 6: Load curves measured for three impact tests performed for a drop of $0.9 \mathrm{~m}$ and a mass of $0.9 \mathrm{~kg}$ in traction.

This model is used to calculate the value of the maximum load applied when a mass falls along a bar as can be seen in Fig.7. A spring is added along the bar in order to simulate a system of a different stiffness connected in series with the bar. In our impact test machine, this system is the Arcan fixture. Brossard proposes three steps during the impact test to determine the maximum load underwent by the one-piece specimen. The first step considers the movement before the impact where the speeds of each solid is defined. Then the second step is the impact itself where the conservation of the momentum is written and resolved in assuming that during the impact there is no variation in the position. The last step consists in writing and in solving the equations of motion after the impact. Finally the maximum load $F_{\max }$ is given by the following expression:

$$
F_{\text {max }}=g(M+\eta m)
$$




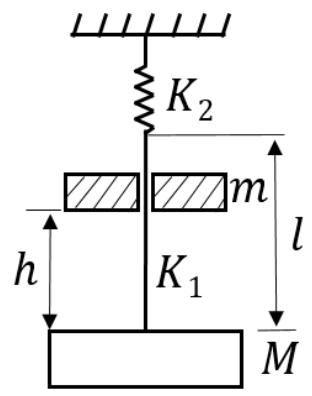

Figure 7: Modeling of the drop weight test in traction proposed in Brossard model [15].

with $g$ the gravitational acceleration, $M$ the impact platform mass equal to $250 \mathrm{~g}, \mathrm{~m}$ the impactor mass and $\eta$ a test rig parameter written with the following expression:

$$
\eta=1+\sqrt{1+2 \frac{h}{f_{s}} \frac{1}{1+\frac{M}{m}}}
$$

with $f_{s}$ the static deflection defined by:

$$
f_{s}=\frac{m g}{K}
$$

with $K$ the stiffness of the system depending on the stiffness of the bar $K_{1}$ and on the global stiffness $K_{2}$ of the Arcan fixture equipped with the one-piece specimen connected in series as described in Fig.7. K can be written:

$$
K=\frac{K_{1} K_{2}}{K_{1}+K_{2}}
$$

where $K_{1}$ is defined by:

$$
K_{1}=\frac{E_{b} S}{l}=2.62 \quad 10^{7} \quad N . m^{-1}
$$

where $E_{b}=70 \mathrm{GPa}$ is the Young's modulus of the bar, $S=0.00049 \mathrm{~m}^{2}$ the bar section and $l=1.31 \mathrm{~m}$ the length of the bar. To measure the global stiffness $K_{2}$ of the Arcan fixture equipped with one-piece specimen, we choose 

with the one-piece specimen are reported in Table 1.

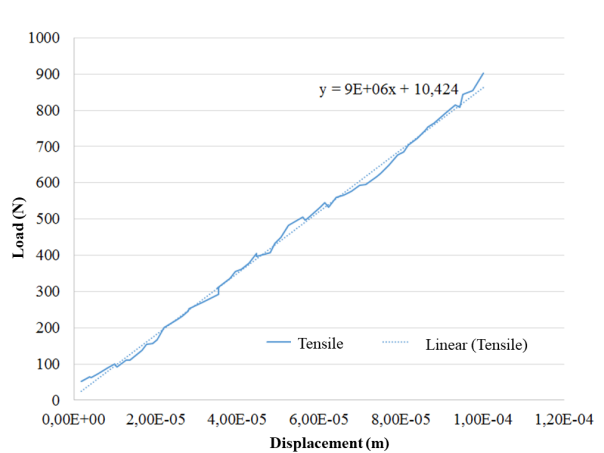

(a) Tensile configuration

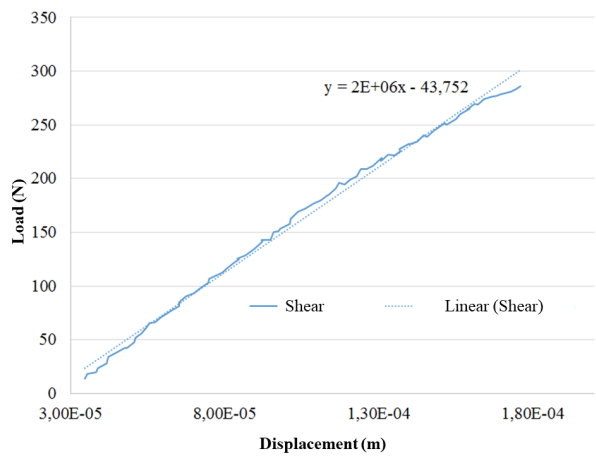

(b) Shear configuration

Figure 8: Measurement of the Arcan fixture stiffness equipped with one-piece specimen.

\begin{tabular}{|l|c|c|}
\hline & Tensile & Shear \\
\hline Rigidity $K_{2} N . m^{-1}$ & $9.10^{6}$ & $2.10^{6}$ \\
\hline
\end{tabular}

Table 1: Arcan fixture stiffness in tensile and shear configurations.

to test it in a tensile machine. Fig.8 describes the load-displacement curve measured in tensile and shear configurations. The linear elastic response is approximated by the best-fit line. The identified stiffness of the Arcan fixture

Then, the $\eta$ and $f_{s}$ parameters can be respectively fully calculated with Equation (2) and Equation (3). Finally the theoretical maximum load seen by the one-piece specimen as a function of the drop height and mass can be calculated with Equation (1). Fig.9 describes values of the maximal load obtained during an impact as a function of the drop height and impactor mass. The theoretical value obtained with Brossard model (lines) are confronted with the experimental results (markers) in tensile and shear configuration. 
The load has the same evolution in traction (Figure 9(a)) and in shearing (Figure 9(b)), it increases at the same time as the mass of the impactor and the drop height. For the same impact conditions (mass, height), the maximum load measured is greater in traction than in shearing. The theoretical load proposed by Brossard [15] is a good approximation of the experimental values measured. The variation coefficient range between the mean experimental forces and the theoretical force is between $2 \%$ and $6 \%$ for traction and between $1 \%$ and $9 \%$ for shear. The maximal deviation observed on a measured value is $25 \%$ and the minimal is $3 \%$. It seems that the deviation increases with the drop height and the mass of the impactor. However, the value of the coefficient of variation remains globally stable over all the experimental tests. The rigidity of the Arcan system has been taken into account, but the intermediate elements load sensor and ball joint have been neglected in order to avoid damaging them. Moreover, the sensor used is a strain gauge type. Results could have been better using a piezoelectric sensor. These sensors are more accurate for measuring signals with dynamic loading. Both remarks can partially explain the discrepancy observed between theoretical and experimental values.

This comparison allows us to validate the dynamic behaviour and to understand the physics of the developed impact test rig in a simplified case (i.e. without the presence of a non linear adhesive in the $K_{2}$ spring behaviour). The test rig design is validated. The static and impact properties measurements of selected adhesives can be launched. 


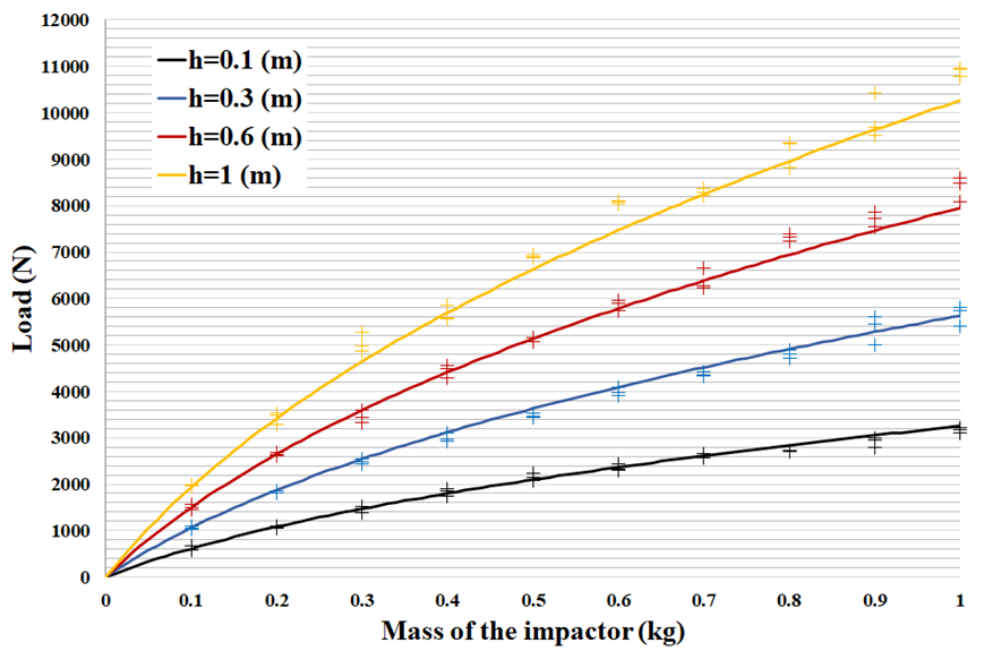

(a) Traction

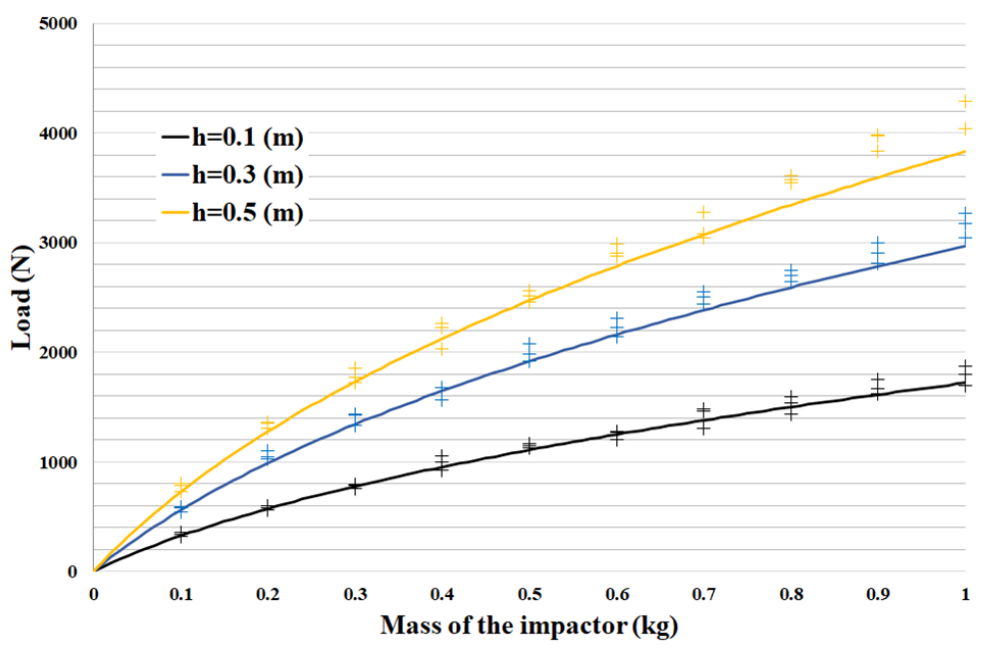

(b) Shearing

Figure 9: Maximal load obtained during an impact as a function of the drop height and the impactor mass. Confrontation between the theoretical values of the Brossard model (lines) and experimental results (markers) in tensile and shear configuration. 


\section{Adhesively-bonded specimens}

\subsection{Adhesives}

Three different adhesives are tested. We have already studied these adhesives to characterize their failure initiation in mode I using the Flexible Initiation Test [9]:

- The Araldite@ AV138M-1/ Hardener HV998 is a brittle epoxy adhesive with a thickness of $0.1 \mathrm{~mm}$. It is a two-component adhesive with an epoxy resin and a hardener. Its polymerization takes place in 24 hours at $23^{\circ} \mathrm{C}$.

- The Permabond 910 is a brittle cyanoacrylate adhesive with a thickness of $0.01 \mathrm{~mm}$. As a methyle based adhesive, it has a fast setting at room temperature through the application of an uniform pressure on the bonded assembly. We wait 24-hour at room temperature to leave the adhesive to fully cure before releasing the applied pressure in order to ensure total polymerization.

- The Scotch-Weld ${ }^{T M} 3 \mathrm{M} 2216 \mathrm{~B} / \mathrm{A}$ is a flexible epoxy adhesive with a thickness of $0.1 \mathrm{~mm}$. It is also a two-component adhesive made of an epoxy resin and an aliphatic diamine hardener. After mixing these two components, polymerization takes place in 7 days at $24^{\circ} \mathrm{C}$. It is possible to accelerate the process by performing a heat treatment

A priori, these adhesives have different mechanical behaviours, ductile versus brittle behaviour, more or less low thickness, different chemical bases. For each adhesive, the shear strength $\sigma_{s}$ and the impact strength $I_{s}$ given by the manufacturer are related in Table 2. 


\begin{tabular}{|c|c|c|c|}
\hline Adhesive & Type & $\sigma_{s}(\mathrm{MPa})$ & $I_{s}\left(\mathrm{kJ.m}^{-2}\right)$ \\
\hline Araldite AV138/HV998 & Brittle epoxy & $14(\mathrm{ISO} 4587)$ & - \\
\hline Permabond 910 & Brittle cyanoacrylate & $14($ ISO4587) & $3-5$ (ASTM D-950) \\
\hline 3M Scotch-Weld 2216 B/A & Flexible epoxy & 27 (EN2243-1) & - \\
\hline
\end{tabular}

Table 2: Adhesive properties: shear strength $\left(\sigma_{s}\right)$ and impact strength $\left(I_{s}\right)$

\subsection{Sample geometries}

The substrates take the form of cylindrical samples, they are machined in Aluminium 2017 whose mechanical properties are reported in table 3. The total height of the aluminium samples includes the height of two half aluminium samples and the thickness of the adhesive joint as related in Fig.10. The height is set to a constant value equal to $64 \mathrm{~mm}$. The geometry of these samples, in tensile configuration, ensures an axisymetrical stress field along the interface.

\begin{tabular}{|c|c|c|}
\hline$E(\mathbf{G P a})$ & $\sigma_{y}(\mathbf{M P a})$ & $\nu$ \\
\hline 70 & 210 & 0,33 \\
\hline
\end{tabular}

Table 3: Material properties of the Aluminum 2017.

Four conditions are tested, as illustrated in Fig.10, corresponding to four free edge geometries at the interface. First of all, a straight edge (Fig.10(a)) with no defects allows to have an homogeneous stress throughout the interface. Then, the Chamfered edge (45 ) (Fig.10(b)) allows to obtain an infinite stress concentration at the interface. After the rounded edge (Fig.10(c)) allows to have an higher stress concentration at the interface than the straight edge. But, in this case the stress is finite and known. And finally, the beaked 


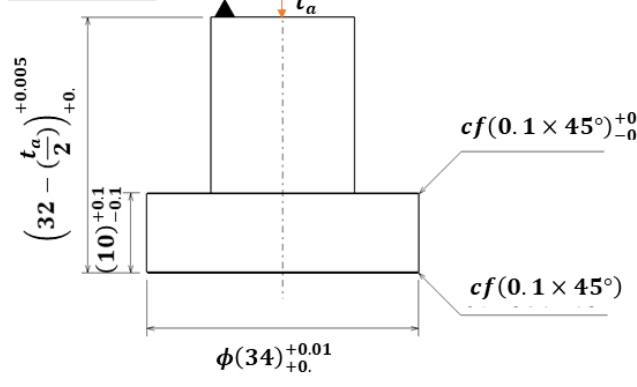

edge (Fig.10(d)) allows to have a stress close to zero on the adhesive joint free edge in order to reduce the edge effects as described in experimental investigations performed by Cognard et al. [14]. The authors have also lead on a numerical study to explain how the beaked edge can be useful to reduce measurement dispersion. It is important to note that the bonding surface remains the same for each stress concentration.

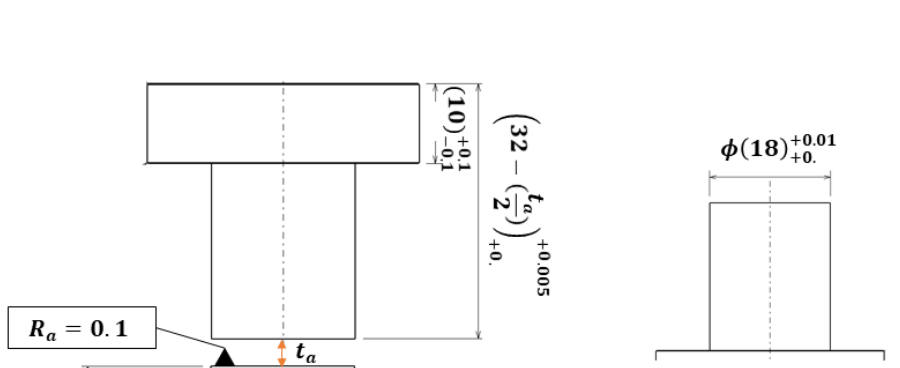

(a) Straight edge

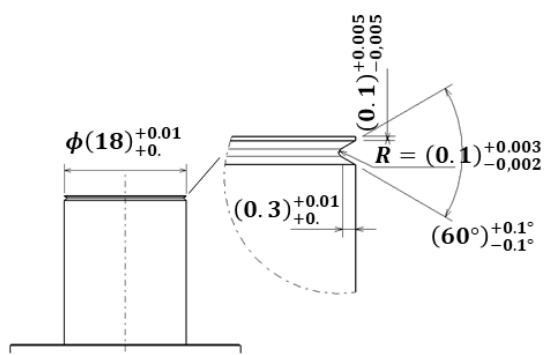

(d) Beaked edge

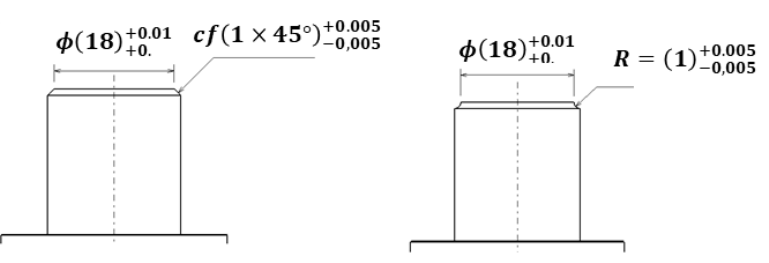

(b) Chamfered edge

(c) Roundededge

Figure 10: Drawing of aluminium cylinder sample and the half-samples with the four free edge conditions.

259

\subsection{Surface preparation}

Before bonding, in order to ensure the effectiveness of the bonding and to decrease measurement dispersion, we control the bonding area quality in imposing a surface finish as the last step of sample manufacturing. The 

surfaces after acetone cleaning.

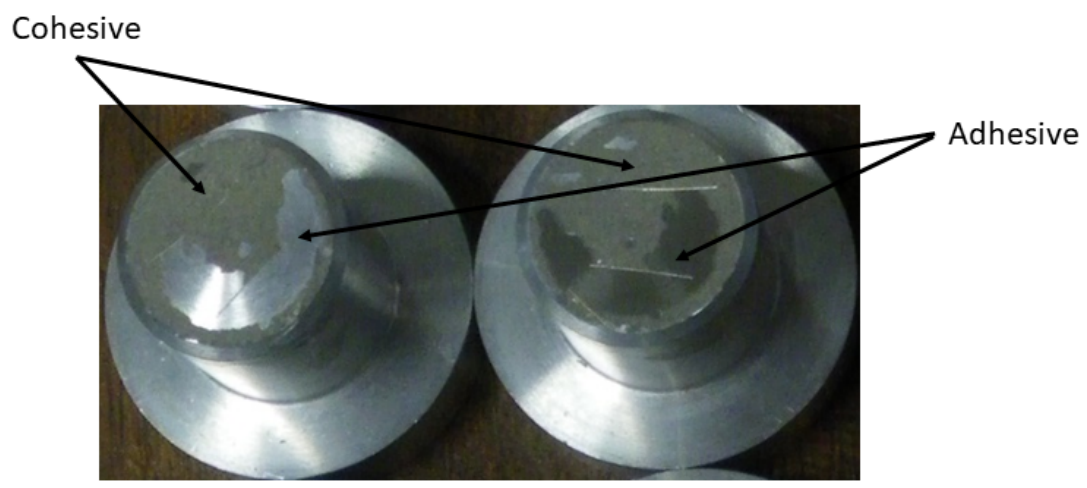
surfaces are cleaned with acetone. In the case of the 3M 2216 adhesive, an additional step is added to avoid mixed fracture (adhesive and cohesive as related in Fig. 11). A primer (Primer 3M 3901) is applied to the aluminium

Figure 11: Example of mixed (adhesive and cohesive) fracture of the 3M 2216 interface without using the primer after acetone cleaning.

268

roughness specified is chosen with an $R_{a}$ of $0.1 \mu \mathrm{m}$. Then the aluminium

\subsection{Bonding protocol}

In these investigations, a bonding protocol is set up in order to minimize bonding defects. Thickness recommended by adhesive manufacturers are used. For each test configuration, a minimum of 5 samples are tested to obtain an admissible statistic. In order to position the aluminium samples and the adhesive, a specific set-up is designed as related in Fig.12. It allows to respect the coaxiality between the two aluminium half samples, to stabilise them during the polymerisation process and to be able to bond five adhesively-bonded assemblies at the same time. The operator in charge of the samples process has to respect very high geometrical tolerances (as 
$$
\text { samples have been bonded, the adhesive joint must be gently cleaned. }
$$

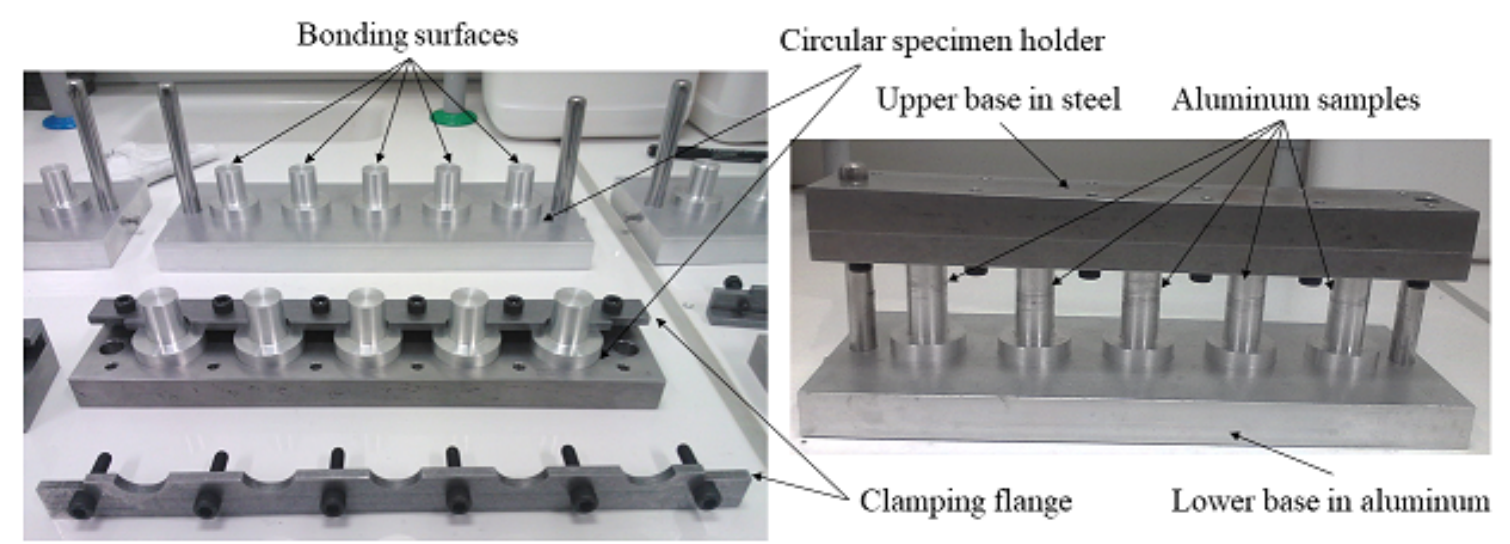

Figure 12: Specific set-up designed to position five adhesively bonded specimens.

described in Fig.10) and has to match specimens to each other after measurements in metrology. For Araldite and 3M 2216 adhesives, we bonded five assemblies at the same time. For cyanoacrylate adhesive, the thickness value is of the same order of magnitude as the geometric specifications, that's why we bonded the samples one by one. The first half sample is placed on the lower base. The adhesive is applied to the bonding surfaces. The second half sample is placed and flanged in order to be fixed on the upper base. Then, a guidance system allows the upper base to be positioned on the lower base and the half samples to be positioned relatively to each other. The upper base is made in steel in order to increase the weight to press the adhesive joints with a good pressure distribution along the five samples. Once the samples have been bonded, the adhesive joint must be gently cleaned.

$m m$ as related in Fig.13(a). With the upper part in steel, same weight is used for each sample to ensure the necessary constant pressure during polymeriza- 

exhibited a cohesive failure as related in Fig.13(b).

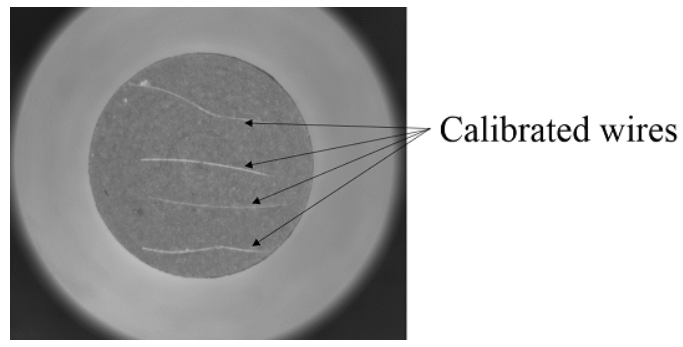

(a) adhesive thickness control

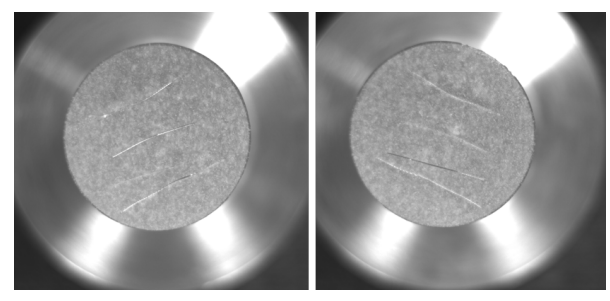

(b) Cohesive fracture

Figure 13: Calibrated wires used to control the adhesive thickness and the cohesive fracture obtained for the adhesive $3 \mathrm{M} 2216$.

tion. Except with the Permabond adhesive, for which the recommended joint thickness is equal to $0.01 \mathrm{~mm}$. Indeed, the cyanoacrylate adhesive polymerizes immediately when both bonded surfaces are pressurized, which allows air to be expelled at the interface and polymerization to be initiated. In all experimental tests presented in this paper, we keep only samples that have

Once the assembly of the sample is performed, it is necessary to wait for the polymerization of the adhesive. In the case of 3M 2216 and Araldite adhesives, polymerization is accelerated by heat treatment. A curing at $40^{\circ} \mathrm{C}$ for 24 hours for the $3 \mathrm{M} 2216$ adhesive and a curing at $40^{\circ} \mathrm{C}$ for 16 hours on the Araldite adhesive are performed. We have chosen this temperature of $40^{\circ} \mathrm{C}$ because it limits the thermal expansion effects, in order to avoid to generate high residual stresses in the adhesive joint during polymerization and cooling.

An optic control is performed, with an optical microscope, to check the alignment between the two substrates especially for cyanoacrylate adhesive. For other adhesives we controlled the free edge geometry of the adhesive joint 

experimental campaigns.

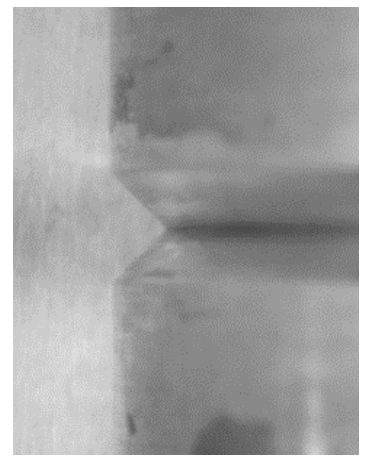

(a) Chamfered edge

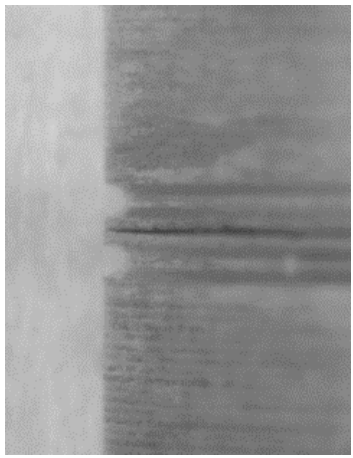

(b) Beaked edge

Figure 14: Bonded interface pictures for Cyanoacrylate adhesive specimens made with a microscope for Chamfered $\left(45^{\circ}\right)$ and beaked edges. 


\begin{tabular}{|c|c|c|c|c|c|c|c|}
\hline Loading & Geometries/Adhesive & \multicolumn{2}{|c|}{ Araldite } & \multicolumn{2}{c|}{ Cyanoacrylate } & \multicolumn{2}{|c|}{ 3M 2216 } \\
\hline \multirow{4}{*}{ Traction } & & Static & Dynamic & Static & Dynamic & Static & Dynamic \\
\cline { 2 - 8 } & Straight edge & 3 & 45 & 3 & 52 & 3 & 45 \\
\cline { 2 - 8 } & Beaked edge & 3 & 45 & 3 & 57 & 3 & 45 \\
\cline { 2 - 8 } & Rounded edge & 3 & 35 & 3 & 39 & 3 & 55 \\
\cline { 2 - 8 } & Chamfered edge $\left(45^{\circ}\right)$ & 3 & 40 & 3 & 37 & 3 & 50 \\
\hline \multirow{4}{*}{ Shear } & & Static & Dynamic & Static & Dynamic & Static & Dynamic \\
\cline { 2 - 8 } & Straight edge & 3 & 30 & 3 & 45 & 3 & 25 \\
\cline { 2 - 8 } & Beaked edge & 3 & 30 & 3 & 46 & 3 & 25 \\
\cline { 2 - 8 } & Rounded edge & 3 & 30 & 3 & 27 & 3 & 30 \\
\cline { 2 - 8 } & Chamfered edge $\left(45^{\circ}\right)$ & 3 & 25 & 3 & 21 & 3 & 30 \\
\hline Total & $\mathbf{9 8 1}$ samples & 24 & 280 & 24 & 324 & 24 & 305 \\
\hline
\end{tabular}

Table 4: Number of samples with cohesive fracture used for the experimental campaign. 


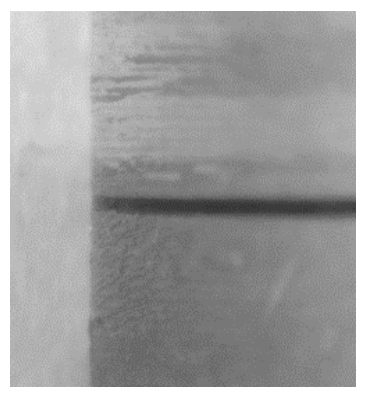

(a) Straight edge

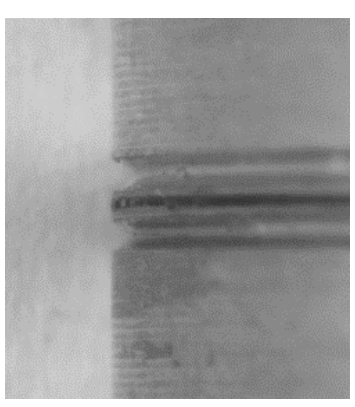

(b) Beaked edge

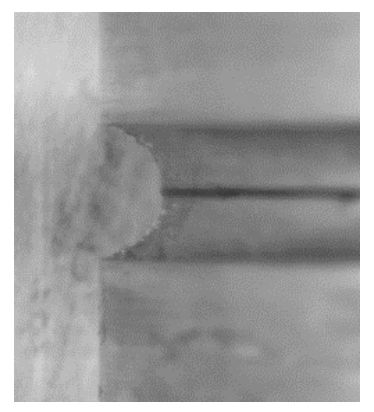

(c) Rounded edge

Figure 15: Bonded interface pictures for 3M 2216 adhesive specimens made with a microscope for straight, beaked and rounded edges. 


\section{Static tests}

In this section, the mechanical behaviour of the three adhesives is investigated in static in mode I and mode II. The average fracture load is measured for the four free edge conditions and a point stress criterion is proposed to determine the critical stress of the adhesives in traction and shearing.

The average fracture load is calculated with a variation coefficient $C V$ (Equation 6) which allows to quantify the data dispersion. This coefficient is calculated with the average of the fracture load $\bar{F}$ and the standard deviation $s$ (Equation 7).

$$
\begin{gathered}
C V=\frac{s}{\bar{F}} \\
s=\sqrt{\frac{\sum_{n}(F-\bar{F})^{2}}{n}}
\end{gathered}
$$

\subsection{Results}

Fig.16 and Fig.17 describe respectively the static test results in mode I and in mode II in providing the average fracture load measured and the standard deviation for the four edge conditions and the three adhesives. Table 5 sums up the facture load values and the variation coefficient $C V$ allowing to quantify the dispersion of data.

The 3M 2216 adhesive has the lowest dispersion across all experimental results. For the majority of configurations its coefficient of variation remains below 10\%. It also appears to be non sensitive to the four different stress concentrations tested. These results were expected for an adhesive with a 


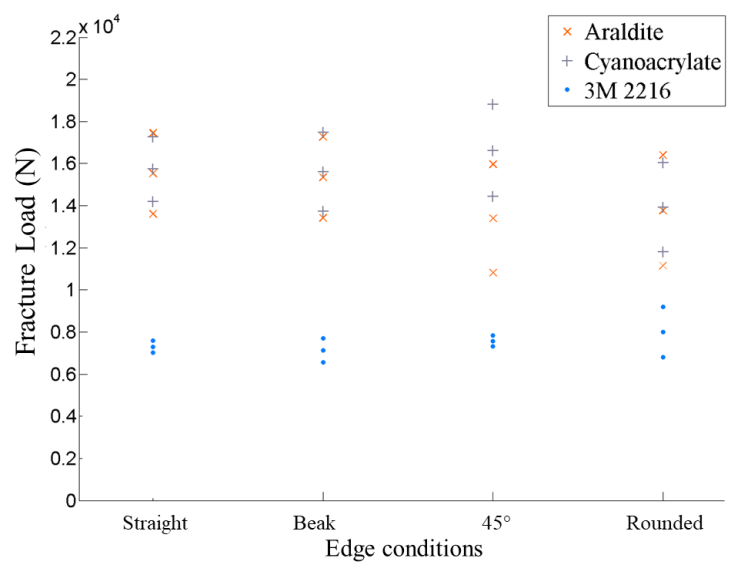

Figure 16: Results of traction static tests (mode I) for the three adhesives: average values and standard deviations of the fracture load.

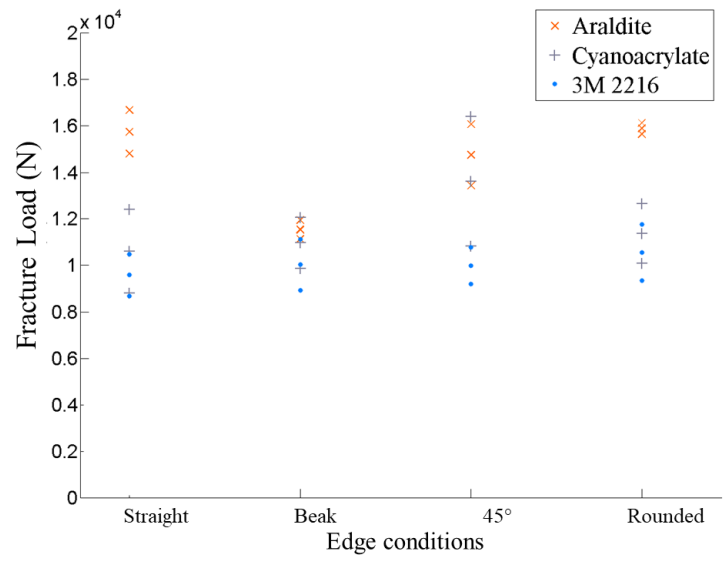

Figure 17: Results of shear static tests (mode II) for the three adhesives: average values and standard deviations of the fracture load.

ductile behaviour. However, its mechanical performances in static remain below the two other adhesives tested.

The Araldite adhesive has a higher dispersion in mode I (greater than $10 \%$ ) but keeps a low dispersion in mode II. In traction, for straight edge and beak edge results are very close and the dispersion is around 10\%. On the 


\begin{tabular}{|c|c||c|c||c|c||}
\hline Adhesives & Edge type & $\bar{F}_{\text {ModeI }}(\mathbf{N})$ & $C V_{\text {ModeI }}(\mathbf{\%})$ & $\bar{F}_{\text {ModeII }}(\mathbf{N})$ & $C V_{\text {ModeII }}$ (\%) \\
\hline \multirow{4}{*}{ Araldite } & Straight & 15520 & 11.1 & 15750 & 5.3 \\
\cline { 2 - 6 } & Beaked & 15340 & 11.7 & 11540 & 3.5 \\
\cline { 2 - 6 } & Chamfered $\left(45^{\circ}\right)$ & 13390 & 17.3 & 14760 & 8 \\
\cline { 2 - 6 } & Rounded & 13770 & 17.1 & 15890 & 1.3 \\
\hline \multirow{4}{*}{ Cyanoacrylate } & Straight & 15730 & 8.8 & 10610 & 15.2 \\
\cline { 2 - 6 } & Beaked & 15590 & 10.8 & 10970 & 9 \\
\cline { 2 - 6 } & Chamfered $\left(45^{\circ}\right)$ & 16610 & 11.7 & 13620 & 18.3 \\
\cline { 2 - 6 } & Rounded & 13920 & 13.6 & 11370 & 10.1 \\
\hline \multirow{3}{*}{3 M 2216 } & Straight & 7302 & 3.5 & 9586 & 8.6 \\
\cline { 2 - 6 } & Beaked & 7129 & 7.2 & 10030 & 10 \\
\cline { 2 - 6 } & Chamfered $\left(45^{\circ}\right)$ & 7576 & 3 & 9984 & 7.3 \\
\cline { 2 - 6 } & Rounded & 7989 & 13.4 & 10560 & 10.2 \\
\hline
\end{tabular}

Table 5: Summary of the fracture load values with the corresponding coefficients of variation for the four type edges and the three adhesives.

other hand the adhesive is sensitive to higher stress concentration ( $45^{\circ}$ edge and rounded edge). In shearing, dispersion remains very low, this adhesive works better in shear configuration. It also seems that the edge effect is smaller in mode II than in mode I. As expected, the dispersion obtained with this brittle adhesive is higher than with the ductile adhesive. And in shear loading, its thickness allows it to better tolerate stress concentrations. The Cyanoacrylate adhesive has in mode I and mode II a very high dispersion, indeed, its coefficient of variation is mostly higher than $10 \%$. This result is expected because the adhesive has a brittle behavior and a very low thickness $(0.01 \mathrm{~mm})$ which makes it very sensitive to bonding defects. It can be noted that its small thickness allows it to be less sensitive to the most severe stress concentration $\left(45^{\circ}\right.$ edge). 


\subsection{Adhesive's critical stresses}

In order to compare the static mechanical strength of the three adhesives, the Point Stress Criterion (PSC) [16] is used. It allows to define the critical stress $\sigma_{c}$ (i.e. the stress necessary to initiate a crack). This criterion is applied at a certain distance from the singularity (here the singularity is the free edge of the adhesive joint), this distance being the characteristic length, $a_{c}$. The criterion can be written:

$$
\sigma\left(a_{c}\right)>\sigma_{c}
$$

If the stress $\sigma$ at the distance $a_{c}$ from the edge is greater than the critical stress $\sigma_{c}$ then the crack will initiate. This length depends on the geometry of the assembly and the thickness of the adhesive joint.

We begin by the mode I. The results on specimens with the straight edge (homogeneous stress concentration) and the chamfered $\left(45^{\circ}\right)$ edge (high stress concentration) are used. Both tests are modeled by a finite elements method using the Abaqus commercial software. The model includes the two Arcan half disks and the aluminium specimen which are considered to be elastic. The glue is not modelled (thin adhesives). The lower part of the fixture is embedded and the average fracture load previously measured is imposed on the upper part of the fixture. Before a study of the influence of the mesh along the interface is carried out. The size of $0.1 \mathrm{~mm}$ is chosen for all the following simulations (Fig.18).

Stress distribution along the interface for both stress concentrations are plotted. The point of curves intersection is used to determine the characteristic length and the critical stress. Fig.19 describes the stress distribution 

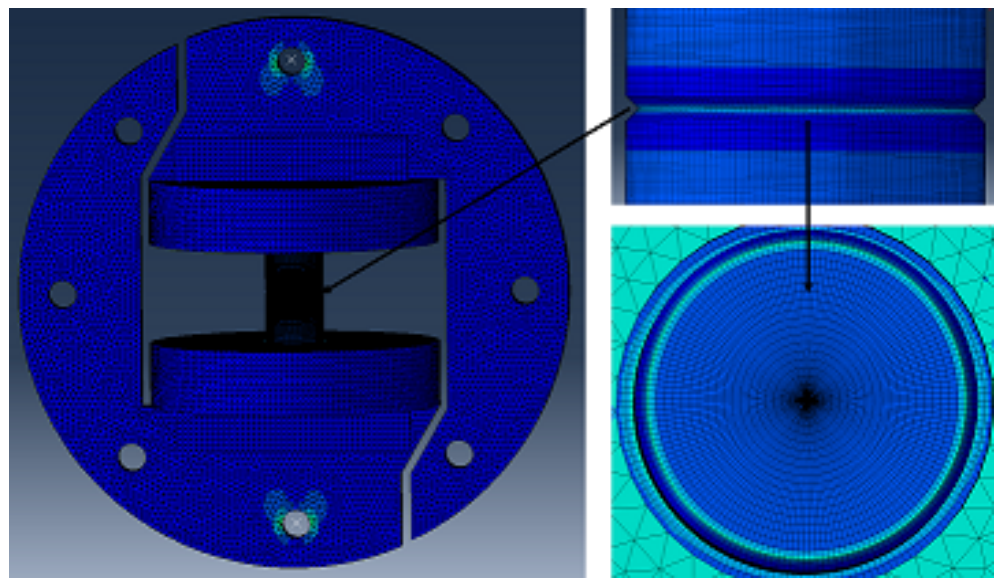

Figure 18: Normal stress distribution for tensile loading of Araldite adhesive with a mesh size of $0.1 \mathrm{~mm}$ at the interface.

normal to the interface for the straight edge and the chamfered $\left(45^{\circ}\right)$ edge for the Araldite adhesive. The intersection point gives the values of $a_{c, I}=0.47$ $m m$ and $\sigma_{c, I}=62.24 M P a$.

Then, we investigate the mode II. The results on specimens with the straight edge and the rounded edge are used. Fig.20 describes the shear stress distribution at the interface for each stress concentration. Nodes of the mesh colored in red correspond to the nodes used to plot the shear stress distribution at the interface. Fig.21 describes the stress distribution for the araldite adhesive in mode II. The intersection point gives the values of $a_{c, I I}=2.85 \mathrm{~mm}$ et $\sigma_{c, I I}=47.5 \mathrm{MPa}$.

In the same way, the point stress criterion is applied for the 3M 2216 and cyanoacrylate adhesives in mode I and mode II. Results are sumed up in Table 6.

Following the experimental campaign and the application of the stress point criteria, it became clear that the ductile adhesive (3M 2216) has a 


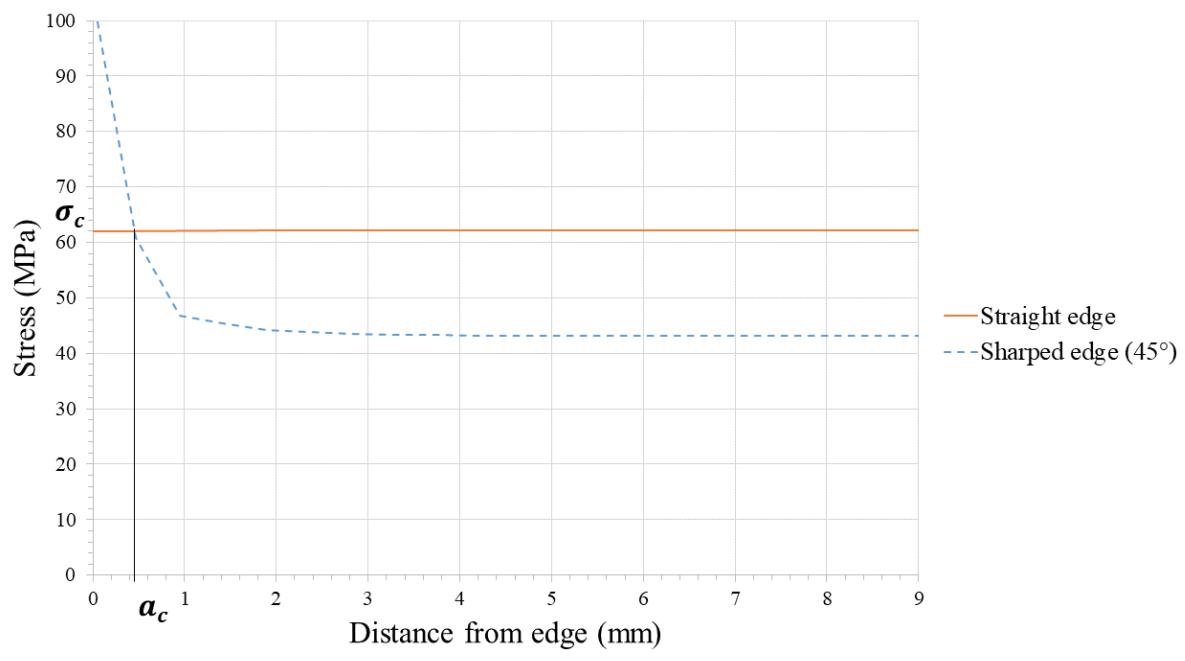

Figure 19: Critical stress identification with normal stress distributions at the interface for tensile loading of Araldite adhesive.

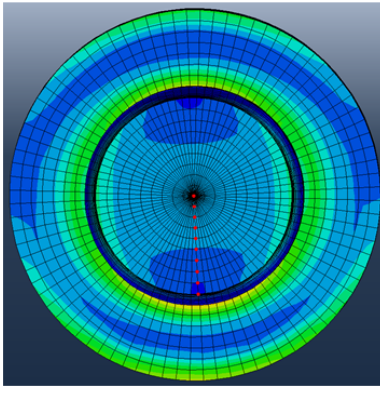

Rounded edge

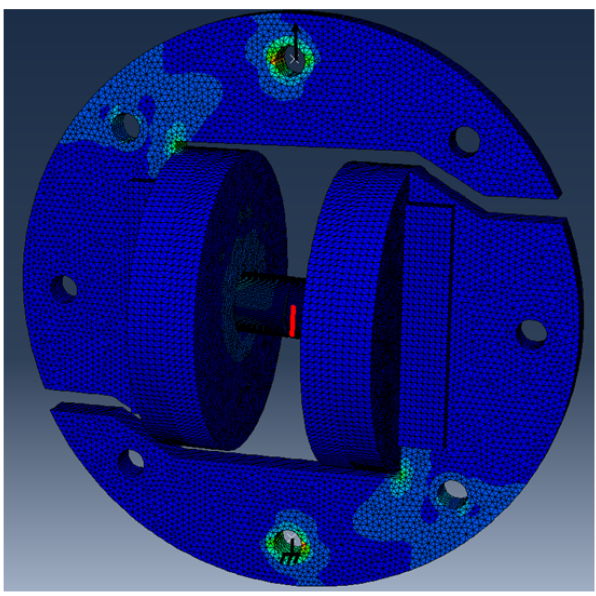

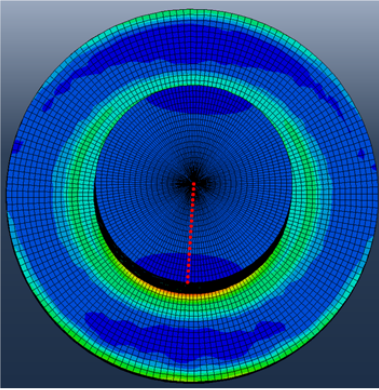

Straight edge

Figure 20: Tangential stress distribution for shear loading of Araldite adhesive at the interface for the rounded edge and the straight edge. 


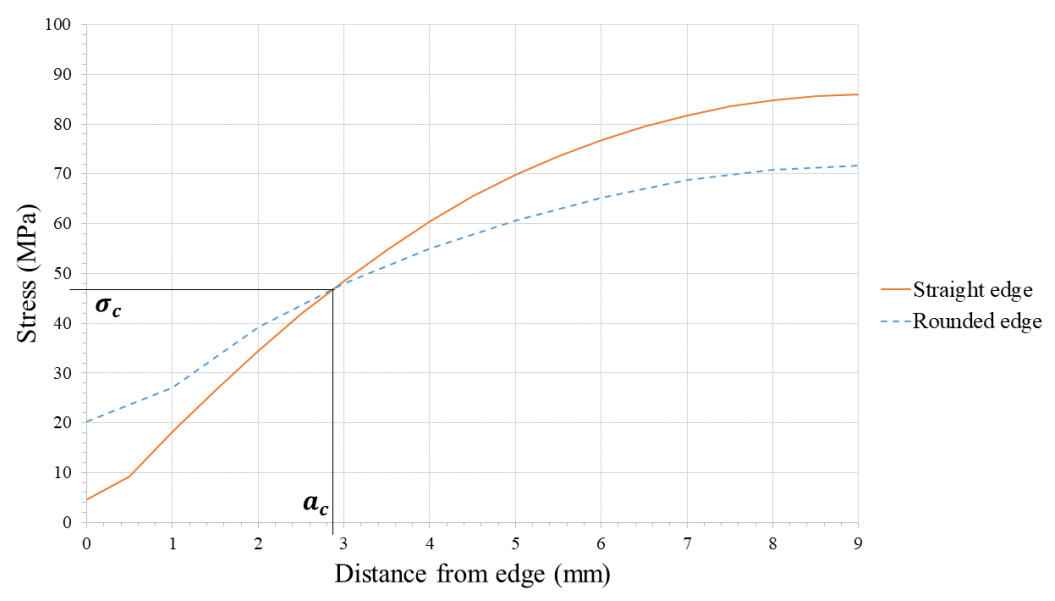

Figure 21: Critical stress identification with tangential stress distributions at the interface for shear loading of Araldite adhesive.

\begin{tabular}{|c|c|c|c|c|}
\hline Adhesive & $a_{c, I}(\mathrm{~mm})$ & $\sigma_{c, I}(\mathrm{MPa})$ & $a_{c, I I}(\mathrm{~mm})$ & $\sigma_{c, I I}(\mathrm{MPa})$ \\
\hline Araldite & 0.47 & 62.2 & 2.85 & 47.5 \\
\hline Cyanoacrylate & 0.78 & 62 & 3.4 & 35.8 \\
\hline 3M 2216 & 0.82 & 28.7 & 3.85 & 36 \\
\hline
\end{tabular}

Table 6: Adhesive's critical stresses identified with the point stress criterion. 
lower static mechanical strength than the two brittle adhesives. Its critical stress is even half as small in traction. Its mechanical strength is better in shearing than in traction. But experimental results obtained with this adhesive are the least dispersed.

For the two brittle adhesives, the mechanical strength is almost the same in mode I. In shear, the Araldite adhesive has a better mechanical strength than the Cyanoacrylate adhesive. They both have better mechanical strength in traction than in shearing. However, these adhesives have a high dispersion which may reduce confidence in their nominal value.

After static tests, brittle adhesives seem to have better mechanical properties. It is now interesting in the following section to confront the impact strength of these adhesives. 


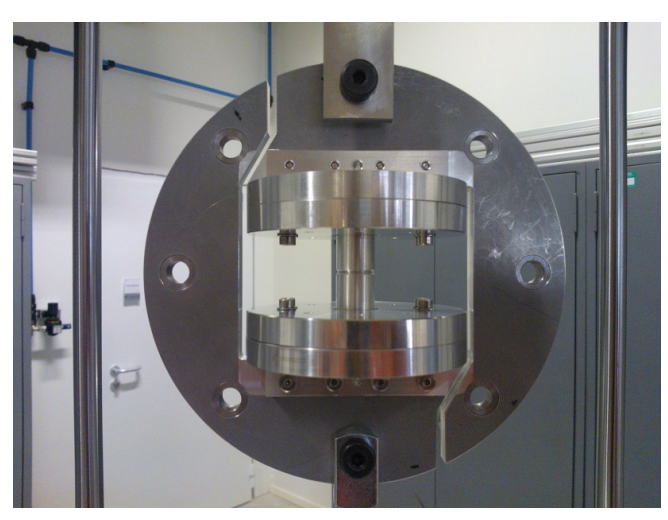

\section{Impact tests}

\subsection{Experimental procedure} (Fig.22(b)) configurations. (a) Traction

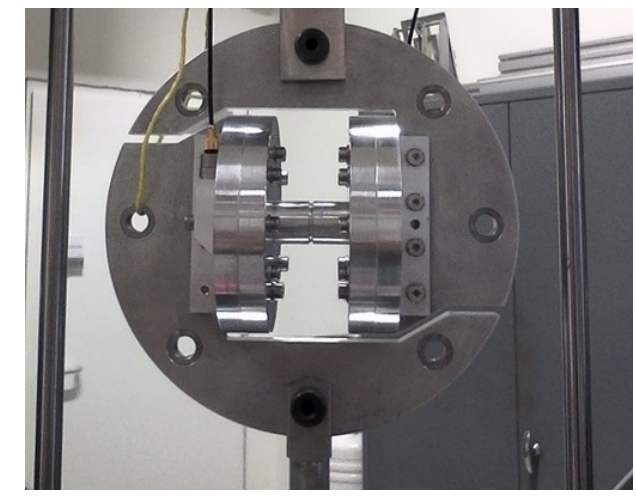

(b) Shearing

Figure 22: Type of solicitation

Impact tests on the three adhesives are performed on the test machine presented in section 3.2. Impact strength of the adhesives are tested, thanks to the integration of the Arcan fixture, in traction (Fig.22(a)) and in shearing

The height of fall of the impactor $h$ is fixed to $1 \mathrm{~m}$ to control the impact speed $v$ as described in Equation 9. Only the mass of the impactor $m_{i}$ is modified to impose an energy on the specimen. The energy $E_{i}$ is defined by the expression of Equation 10:

$$
\begin{gathered}
v=\sqrt{2 g h}=4.43 m . s^{-1} \\
E_{i}=m_{i} g h
\end{gathered}
$$


For each energy level a minimum of five tests are performed. Then the failure ratio $\delta_{f}$ is calculated, as described in Equation 11, with the ratio of the number of specimen broken $N_{b}$ and the total number of specimen tested $N_{t}$ :

$$
\delta_{f}=\frac{N_{b}}{N_{t}}
$$

The evolution of the failure ratio $\delta_{f}$ as a function of the impact energy $E_{i}$ can be displayed on a graph as described in Figure 23. On this curve, we choose to define two characteristic energies: an energy $E_{0}$ which corresponds to the limit of the adhesive's impact strength $(\delta=0 \%)$ (i.e. below this energy the integrity of the specimen is guaranteed); and an impact energy $E_{100}$ which corresponds to the systematical rupture of the adhesive $(\delta=100 \%)$.

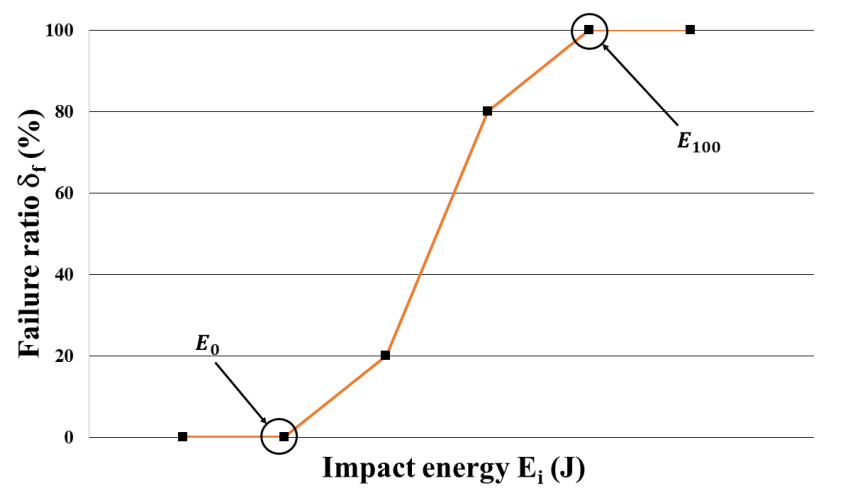

Figure 23: Failure ratio $\delta_{f}$ in function of the impact energy $E_{i}$ with characteristic energies $E_{0}$ and $E_{100}$

The drop tower is approximate but interesting to discriminate selected adhesives. The notion of high strain rate tests and impact tests are two different physics, one concerns a linear strain imposed at high speed and the 
other a strain wave (an instantaneous Dirac). Contrary to Vales et al. [12] we don't try to use the second one to bring us back to the first ones. We choose here to compare impact failure energies for three adhesives under the same conditions. If we wanted to be quantitative, we would have chosen a Hopkinson type test more suited to controlling the wave and its path as described in P.Bailly book [17]. We propose to define a relative impact strength $I_{S 0}$, not describing the intrinsic properties of the adhesive, but allowing to compare them under the same conditions. $I_{S 0}$ is calculated in using the characteristic energies $E_{0}$ and the surface $S$ of the adhesive joint with the following expression:

$$
I_{S 0}=\frac{E_{0}}{S}
$$

\subsection{Results}

\subsubsection{Araldite}

Fig.24 describes impact test results obtained in traction and shearing configurations for the Araldite adhesive. In these experimental results, we observe, as expected, three distinct phases : the first one is an impact energy zone where samples do not break until the impact energy called $E_{0}$; then a second phase where the failure ratio evolves quasi linearly between $\delta_{f}=0 \%$ and $\delta_{f}=100 \%$; and a last phase beginning at $E_{100}$ where samples break systematically. The degradation of the impact strength is gradual and linear for the araldite adhesive. We observe also that the araldite adhesive has a better impact strength in traction than in shearing in case of straight edge and $45^{\circ}$ edge. Moreover, characteristic energies for the same type of loading are higher in the case without stress concentration. 


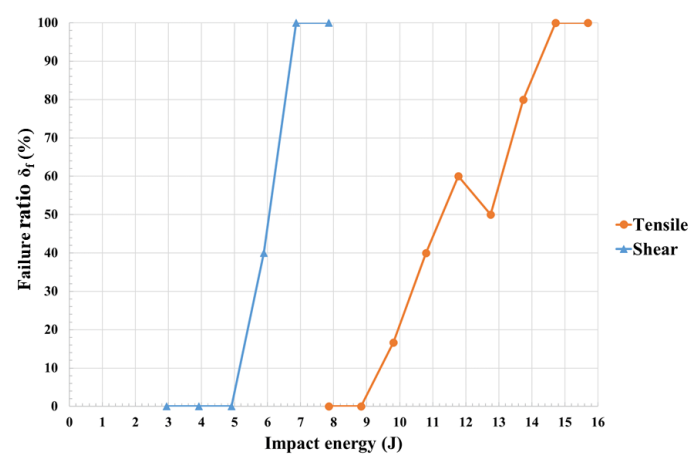

(a) Straight edge

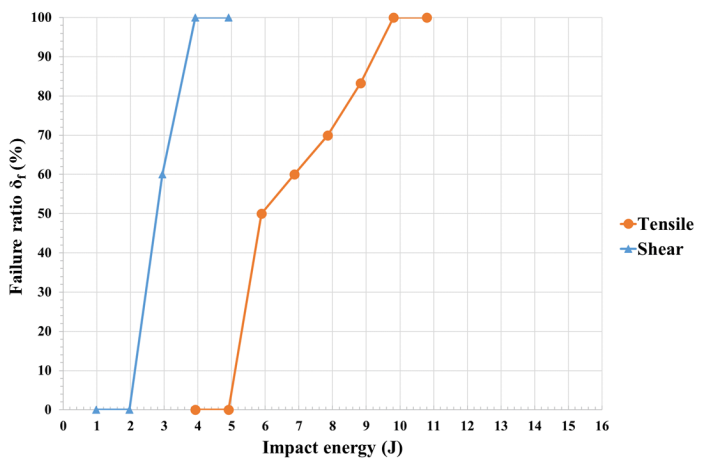

(b) Chamfered edge $\left(45^{\circ}\right)$

Figure 24: Failure ratio $\delta_{f}$ in function of the impact energy of tensile and shear impact tests for the Araldite adhesive. For the straight edge (a) and the chamfered edge (b). 
Fig.25 describes the impact test results in traction and in shearing of Araldite adhesive for the four different edge geometries. For each stress concentration, the failure ratio as a function of the impact energy evolves in the same way. The transition zone seems more linear in shearing than in traction. A change in impact strength behaviour is observed according to the different edge geometries. Globally, traction and shearing characteristic energies $E_{0}$ and $E_{100}$ decrease as the severity of the stress concentration increase.

In traction energy $E_{0}$ is divided by two between the condition with no stress concentration and the infinite stress concentration. The Araldite impact strength is very sensitive to the stress concentration as already observed in static tests. But for a brittle adhesive the value of relative impact strength $I_{S 0}$ measured is very high for no stress concentration condition.

Table 7 sums up characteristic impact energies and relative impact strengths $I_{S 0}$ of araldite adhesive measured for each stress concentration. On the series of tensile tests, the fracture facies showed cohesive fractures, which validates the impact strength measured as described in Fig.26. 


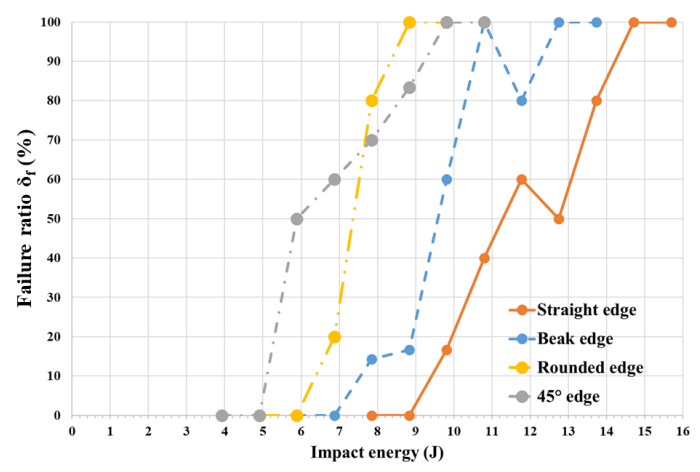

(a) Traction

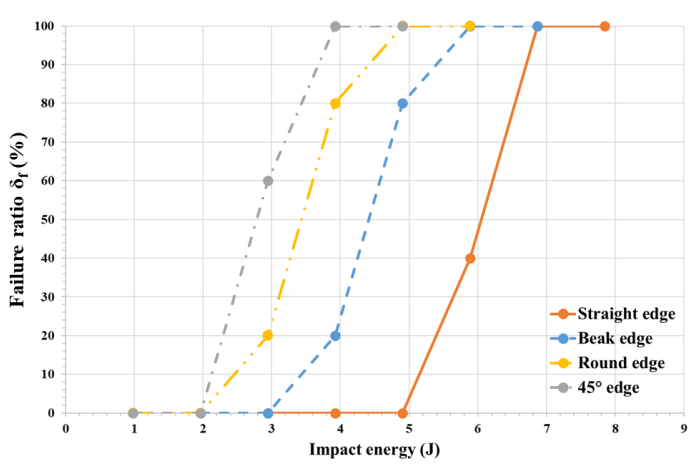

(b) Shearing

Figure 25: Failure ratio $\delta_{f}$ in function of the impact energy for the Araldite adhesive. Confrontation between the different edge geometries (or stress concentrations). In tensile configuration (a) and shear configuration (b).

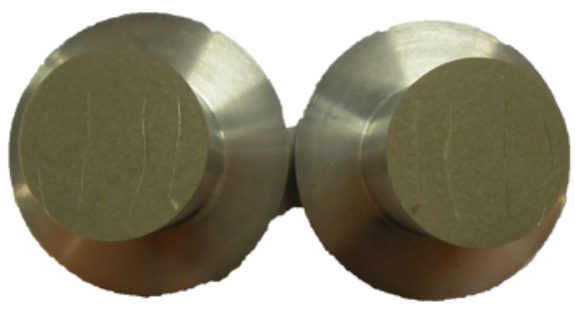

Figure 26: Fracture facies observed on Araldite joint after an impact test in traction. 


\begin{tabular}{|c|c|c|c|c|}
\hline \multicolumn{2}{|c|}{ Araldite } & $E_{0}(J)$ & $E_{100}(J)$ & $I_{S 0}\left(k J . m^{-2}\right)$ \\
\hline \multirow{4}{*}{ Traction } & Straight edge & 8.83 & 14.71 & 34.7 \\
\cline { 2 - 5 } & Beaked edge & 6.87 & 10.79 & 27 \\
\cline { 2 - 5 } & Rounded edge & 5.89 & 8.83 & 23.1 \\
\cline { 2 - 5 } & Chamfered edge $\left(45^{\circ}\right)$ & 4.91 & 9.81 & 19.3 \\
\hline \hline \multirow{4}{*}{ Shearing } & Straight edge & 4.91 & 6.87 & 19.3 \\
\cline { 2 - 5 } & Beaked edge & 2.94 & 5.89 & 11.6 \\
\cline { 2 - 5 } & Rounded edge & 1.96 & 4.91 & 7.7 \\
\cline { 2 - 5 } & Chamfered edge $\left(45^{\circ}\right)$ & 1.96 & 3.92 & 7.7 \\
\hline
\end{tabular}

Table 7: Impact energies measured and relative impact strengths calculated for the Araldite adhesive. 


\subsubsection{Cyanoacrylate}

Fig.27 describes impact test results obtained in traction and in shearing configurations for the Cyanoacrylate adhesive. As previously, we observe also three distinct phases. The evolution of the failure ratio makes it possible to identify energies $E_{0}$ and $E_{100}$. The degradation of the impact strength is also gradual and linear, but the transition phase here seems more abrupt. We observe also that the Cyanoacrylate adhesive has a better impact strength in traction than in shearing in case of straight edge and $45^{\circ}$ edge. On the other hand, Cyanoacrylate seems less sensitive than the araldite face to the different edge conditions.

But this behaviour may be due to the bonding process, which is more difficult to control. The very low thickness of the adhesive joint $(0.01 \mathrm{~mm})$ which made it very difficult to observe fracture facies (Figure 28). Specimens with adhesive and not cohesive fracture could not be removed. Indeed, during the tests, some specimens which seemed to describe a lack of adhesive on facture facies has a very good strength while others where adhesive was visible on the complete surface after fracture broke at low energies.

Fig.29 describes the impact test results in traction and shearing of Cyanoacrylate adhesive for the four different edge geometries. For each stress concentration, the failure ratio as a function of the impact energy evolves in the same way. A change in impact strength behaviour is observed according to the different edge geometries. The transition zone seems less chaotic in shearing than in traction. In traction, we do not observe a clear difference between the different stress concentrations. For both loading, the beaked edge has the best impact strength. Contrary to static case, the cyanoacrylate seems 
very sensitive to most severe stress concentrations and the beak edge gives the best results.

Table 8 sums up the characteristic impact energies and the relative impact strengths $I_{S 0}$ of Cyanoacrylate adhesive measured for each stress concentration.

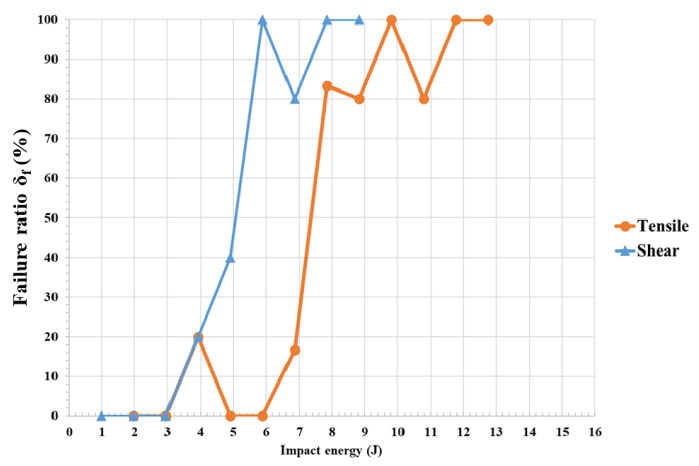

(a) Straight edge

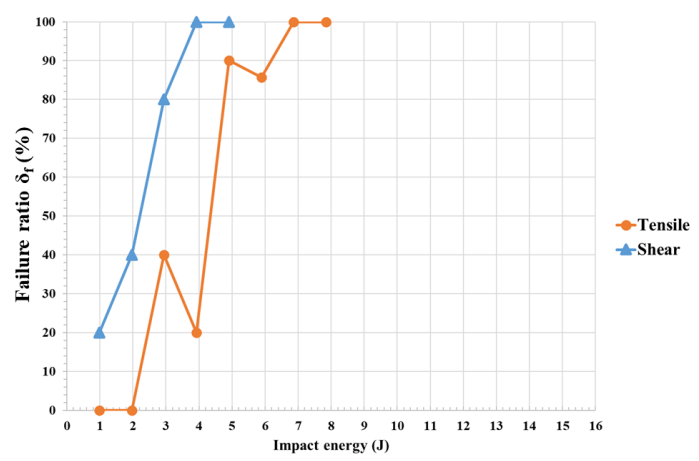

(b) Chamfered edge $\left(45^{\circ}\right)$

Figure 27: Failure ratio in function of the impact energy measured with tensile and shear impact tests for the Cyanoacrylate adhesive. 

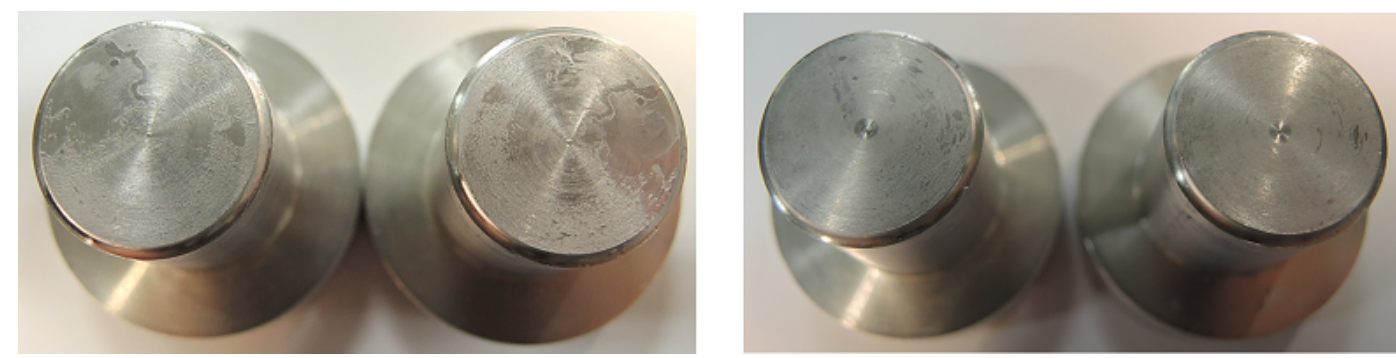

Figure 28: Fracture facies observed on Cyanoacrylate joint after an impact test in traction.

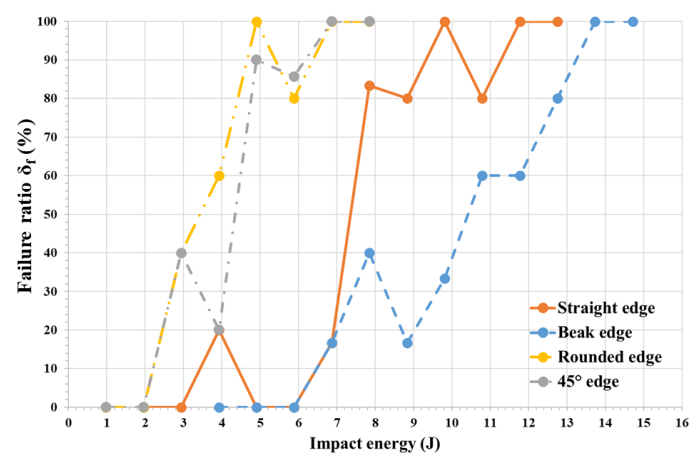

(a) Traction

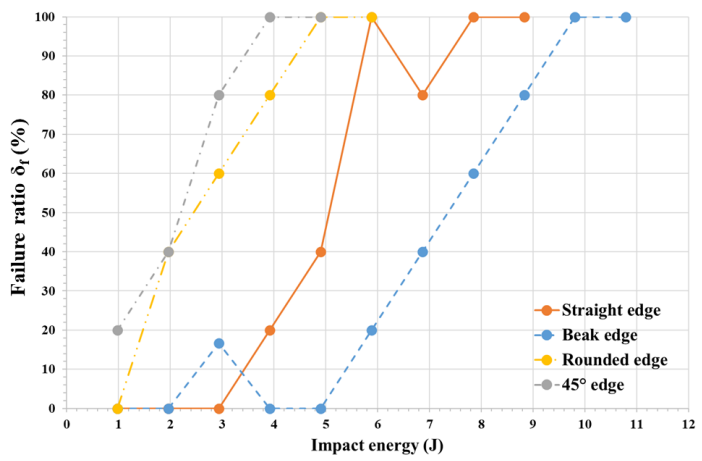

(b) Shearing

Figure 29: Failure ratio $\delta_{f}$ in function of the impact energy for the Cyanoacrylate adhesive. Confrontation between the different edge geometries (or stress concentrations). In tensile configuration (a) and shear configuration (b). 


\begin{tabular}{|c|c|c|c|c|}
\hline \multicolumn{2}{|c|}{ Cyanoacrylate } & $E_{0}(\mathrm{~J})$ & $E_{100}(\mathrm{~J})$ & $I_{S 0}\left(k J . m^{-2}\right)$ \\
\hline \multirow{4}{*}{ Traction } & Straight edge & 2.94 & 11.77 & 11.6 \\
\cline { 2 - 5 } & Beaked edge & 5.89 & 13.73 & 23.1 \\
\cline { 2 - 5 } & Rounded edge & 1.96 & 4.91 & 7.7 \\
\cline { 2 - 5 } & Chamfered edge $\left(45^{\circ}\right)$ & 1.96 & 6.87 & 7.7 \\
\hline \hline \multirow{4}{*}{ Shearing } & Straight edge & 2.94 & 5.89 & 11.6 \\
\cline { 2 - 5 } & Beaked edge & 1.96 & 9.81 & 7.7 \\
\cline { 2 - 5 } & Rounded edge & 0.98 & 4.91 & 3.9 \\
\cline { 2 - 5 } & Chamfered edge $\left(45^{\circ}\right)$ & - & 3.92 & - \\
\hline
\end{tabular}

Table 8: Impact energies measured and relative impact strengths calculated for the Cyanoacrylate adhesive. 


\subsubsection{M 2216}

Fig.30 describes impact test results obtained in tensile and shearing configuration for the 3M 2216 adhesive. As before, the evolution of the failure ratio makes it possible to identify energies $E_{0}$ and $E_{100}$. The degradation of the impact strength is gradual and linear for the 3M 2216 adhesive. 3M 2216 has also a better impact strength in traction than in shearing in case of straight edge and $45^{\circ}$ edge. Moreover, characteristic energies for the same type of loading are higher in the case without stress concentration. On the other hand, the edge geometries used at the interface seem to have any influence on impact strength results.

Fig.31 describes the impact test results in traction and in shearing of $3 \mathrm{M}$ 2216 adhesive for the four different edge geometries. In traction, we don't observe any difference between the different stress concentrations. Indeed, the characteristic energies $E_{100}$ are identical for the four stress concentrations, only energy $E_{0}$ varies. But in this case, the evolution of the failure ratio between characteristic energies $E_{0}$ and $E_{100}$ is not linear. This transition zone is chaotic and presents dispersion for 3M 2216 adhesive. In shearing, we don't observe any difference between the different stress concentrations but we find again the linear transition. Contrary to static results, it appears to be sensitive to the different stress concentrations tested.

Table 9 sums up the characteristic impact energies and the relative impact strengths $I_{S 0}$ of $3 \mathrm{M} 2216$ adhesive measured for each stress concentration. 


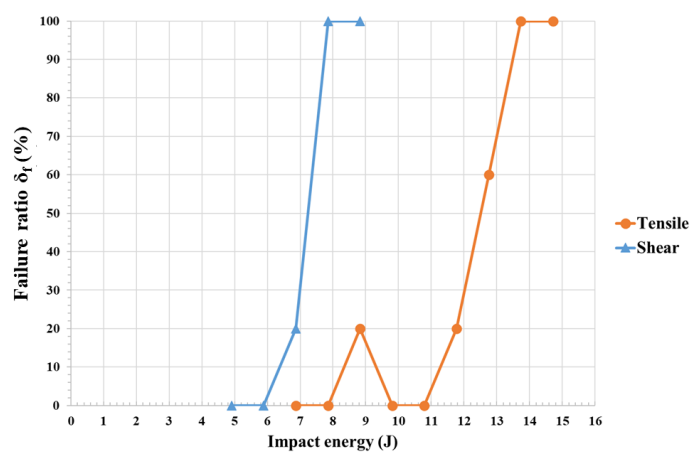

(a) Straight edge

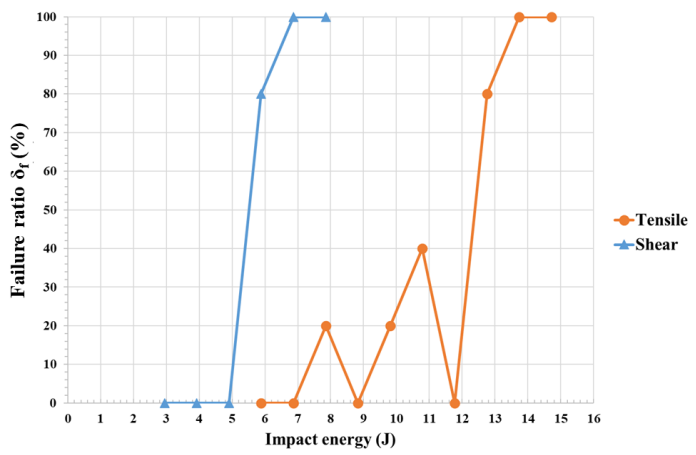

(b) Chamfered edge $\left(45^{\circ}\right)$

Figure 30: Failure ratio in function of the impact energy measured with tensile and shear impact tests for the 3M 2216 adhesive. 


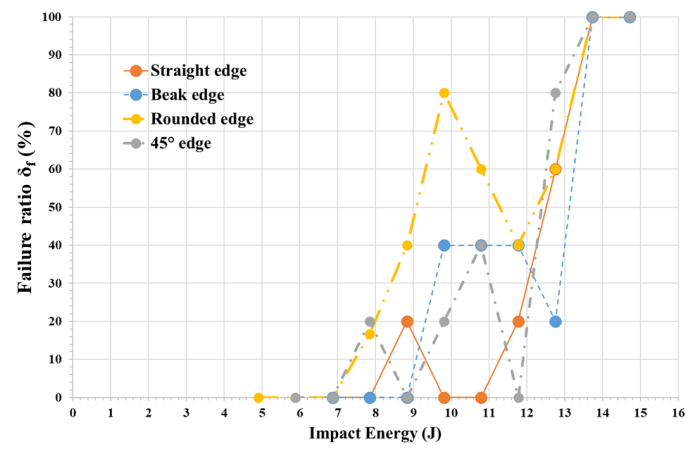

(a) Traction

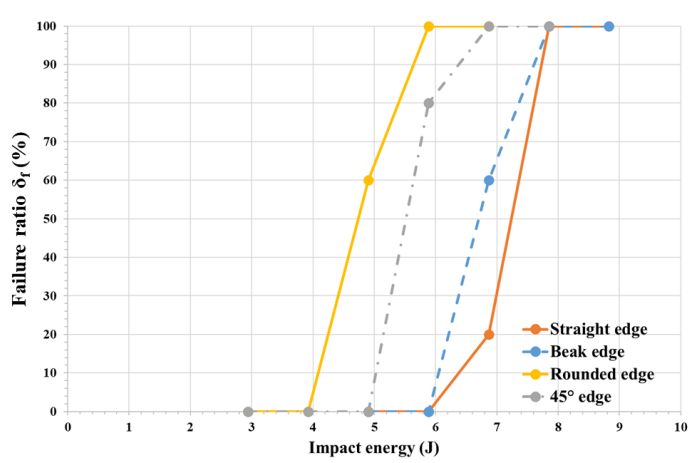

(b) Shearing

Figure 31: Failure ratio $\delta_{f}$ in function of the impact energy for the 3M 2216 adhesive. Confrontation between the different edge geometries (or stress concentrations). In tensile configuration (a) and shear configuration (b). 


\begin{tabular}{|c|c|c|c|c|}
\hline \multicolumn{2}{|c|}{ 3M 2216 } & $E_{0}(\mathrm{~J})$ & $E_{100}(\mathrm{~J})$ & $I_{S 0}\left(k J . m^{-2}\right)$ \\
\hline \multirow{4}{*}{ Traction } & Straight edge & 7.85 & 13.73 & 30.8 \\
\cline { 2 - 5 } & Beaked edge & 8.83 & 13.73 & 34.7 \\
\cline { 2 - 5 } & Rounded edge & 6.87 & 13.73 & 27 \\
\cline { 2 - 5 } & Chamfered edge $\left(45^{\circ}\right)$ & 6.87 & 13.73 & 27 \\
\hline \hline \multirow{4}{*}{ Shearing } & Straight edge & 5.89 & 7.85 & 23.1 \\
\cline { 2 - 5 } & Beaked edge & 5.89 & 7.85 & 23.1 \\
\cline { 2 - 5 } & Rounded edge & 3.92 & 5.89 & 15.4 \\
\cline { 2 - 5 } & Chamfered edge $\left(45^{\circ}\right)$ & 4.91 & 6.87 & 19.3 \\
\hline
\end{tabular}

Table 9: Impact energies measured and relative impact strengths calculated for the $3 \mathrm{M}$ 2216 adhesive. 


\subsection{Confrontation between adhesives}

Fig.32 et Fig.33 describe the comparison of the three tested adhesives according to the different free edge conditions in traction and in shearing, respectively. In traction, Cyanoacrylate always seems to perform less well than the other two adhesives. Araldite and 3M 2216 seem comparable for the straight edge and the beaked edge. For more severe stress concentrations araldite is much less performing. On the other hand, in shearing the adhesives are better grouped together, but the two brittle adhesives seem to perform in the same way. It seems that thickness does not play a fundamental role in impact strength. Whereas in static tests, it allows to better accommodate the effect of the different stress concentrations.

Finally, the flexible adhesive (3M 2216) has the best impact strength. The free edge geometry at the interface has a little influence on its strength. Contrary to brittle adhesives, which exhibit different impact strength in function of free edge conditions. Cyanoacrylate (very low thickness of $0.01 \mathrm{~mm}$ ) has a better strength with beaked edge and the Araldite has a better strength with straight edge. 


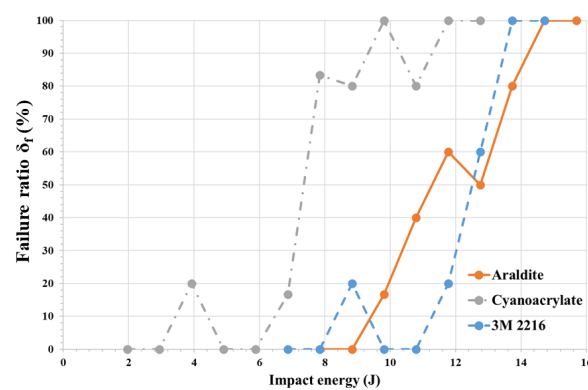

(a) Straight edge

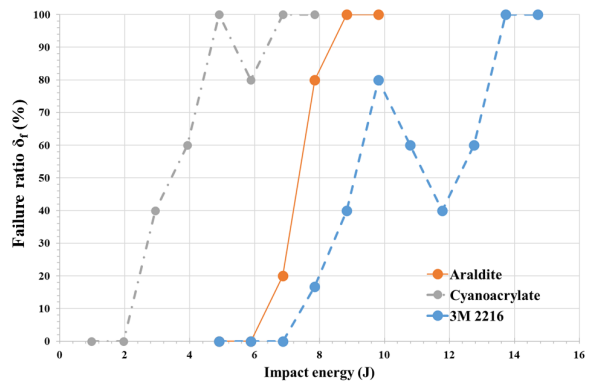

(c) Rounded edge

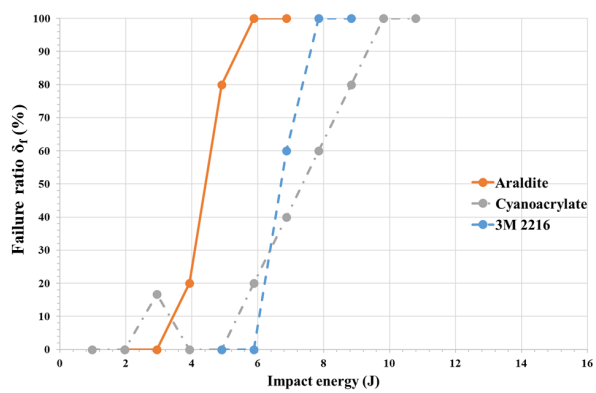

(b) Beaked edge

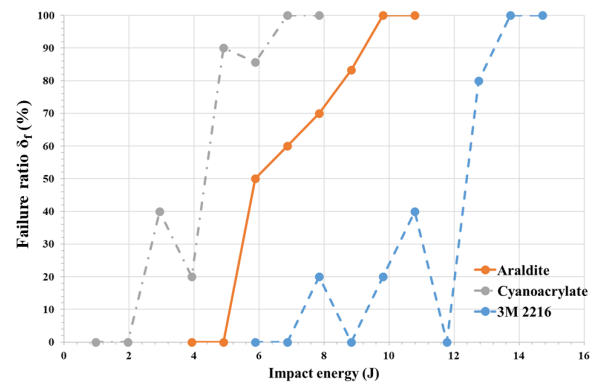

(d) Chamfered edge $\left(45^{\circ}\right)$

Figure 32: Comparison of the behaviour of adhesives under tensile impact loading for different free edge geometries. 


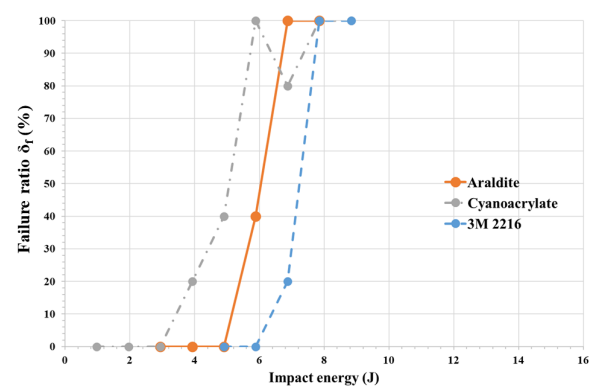

(a) Straight edge

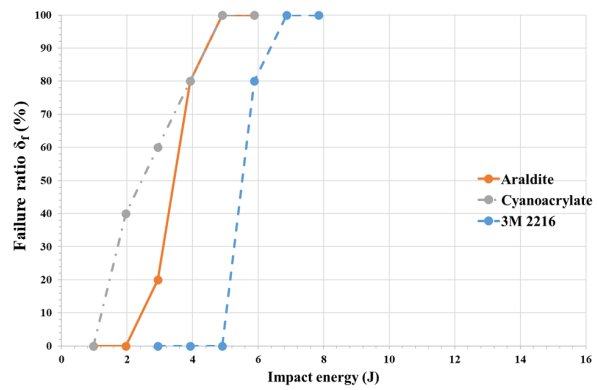

(c) Rounded edge

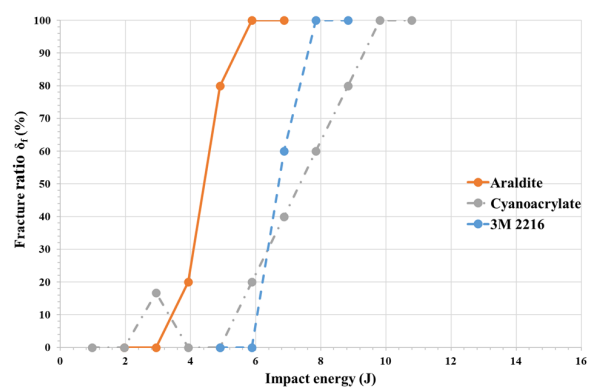

(b) Beaked edge

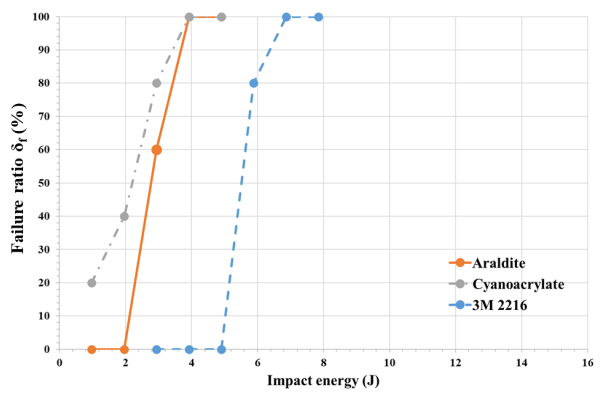

(d) Chamfered edge $\left(45^{\circ}\right)$

Figure 33: Comparison of the behaviour of adhesives under shear impact loading for different free edge geometries. 


\section{Conclusions}

The paper presents the development of an experimental method to characterize and to compare the dynamic behaviour of adhesives by coupling a drop tower and a modified Arcan device. The test rig is used to create a soft impact characterised by the transformation of kinetic energy into a dynamic tensile loading thanks to the conservation of the quantity of movement and the minimisation of unwanted phenomena (friction, wave reflection, etc.).

A first confrontation with an analytical model made it possible to validate the behaviour of the test bench and to quantify the deviations of the impact system. The introduction of the modified Arcan set-up allows us to carry out our tests in tensile and shear configurations on specimens with different free edge geometries.

Then, static tests results were used to determine the critical tensile and shear stresses $\left(\sigma_{c, I} \& \sigma_{c, I I}\right)$ of each adhesive using a stress point criterion. These values are plotted on the vertical axis of the graphs described in Fig.34.

The second experimental campaign consisted of impacting our adhesive joints in traction and shear for 4 different edge geometries (straight edge, sharp edge, beak edge, rounded edge). These impact tests were used to define the characteristic energies $\left(E_{0}\right.$ and $\left.E_{100}\right)$ specific to each adhesive. The relative impact strength values $I_{S 0}$ are calculated for each adhesive and each edge geometry. Results are plotted on the horizontal axis of the graphs shown in Fig.34.

Static tests have demonstrated that the influence of the edge geometry is very small for the ductile adhesive (3M 2216) contrary to the two brittle adhesives (Cyanoacrylate \& Araldite). In static, the ductile adhesive showed 
a lower mechanical strength with little scattered results in comparison to the two brittle adhesives. This result is more true in traction than in shear.

Impact tests have revealed that the geometry of the interface's free edge has an influence on the impact strength of brittle and ductile adhesives. The ductile adhesive this time has a slightly higher mechanical strength (20\%) than the brittle adhesives tested.
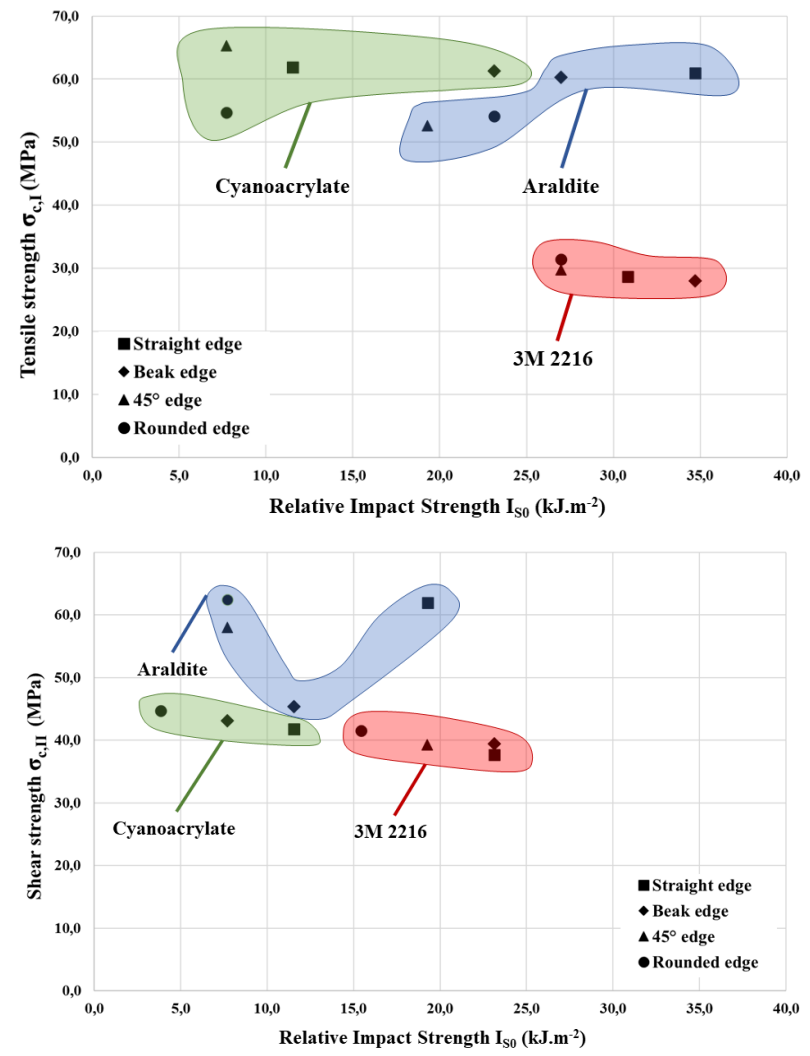

Figure 34: Static $\left(\sigma_{c, I} \& \sigma_{c, I I}\right)$ and dynamic $\left(I_{S 0}\right)$ mechanical properties of the three adhesives in tensile and shear.

The two graphs in Fig.34, one for tensile and the other for shear, illustrate 
3M 2216 adhesive is considerably lower in static performance for a relatively low benefit in dynamic performance. If, for example, the Araldite adhesive is chosen and compared with 3M 2216, assuming good control of the edge conditions: the static tensile strength is doubled, the static shear strength is multiplied by 1.5 and the dynamic shear strength is reduced by only $20 \%$.

This experimental program has demonstrated that the static and dynamic behaviours of adhesives are different. The best compromise between static and dynamic behaviours is not necessarily easy to find. In our case, the adhesive have to be used to integrate direct bonded optical spatial systems that are subjected to high dynamic loads in the launcher. Our choice here is based on Araldite, with a fine control of the edge conditions and an increase in the bonding surface.

Interesting prospects could be investigated: the first concerns the validation of these results on a complex bonded structure undergoing dynamic loading (vibrating pot). The second concerns the effect of the viscoelastic properties of the adhesive on its strength under dynamic loading, which for the moment does not seem very clear to us. And the third, more fundamental, concerns the discussion of a dynamic experimental criterion that can be used to validate our bonding within a finite element simulation of the dynamic loading of the bonded structure, equivalent to the static failure criterion (stress point, average stress,...). 


\section{Acknowledgments}

The research has been performed at the Laboratory of Mechanics and Acoustics of Aix Marseille University with the CNES and Thales Alenia Space financial support.

\section{References}

[1] J. Machado, E. Marques, L. F. da Silva, Adhesives and adhesive joints under impact loadings: An overview, The Journal of adhesion 94 (6) (2018) 421-452.

[2] M. You, M.-B. Li, Y.-L. Yuan, G. Lin, F.-W. Ma, L.-F. Du, S.-J. Tang, Review of experimental techniques for impact property of adhesive bonds, International Journal of Adhesion and Adhesives (2020) 102620.

[3] B. R. K. Blackman, A. J. Kinloch, F. R. Sanchez, W. S. Teo, J. G. Williams, The fracture behaviour of structural adhesives under high rates of testing, Engineering Fracture Mechanics 76 (18) (2009) 28682889 .

[4] A. Beevers, M. Ellis, Impact behaviour of bonded mild steel lap joints, International Journal of Adhesion and Adhesives 4 (1) (1984) 13-16.

[5] L. Goglio, Impact Tests, Springer Berlin Heidelberg, Berlin, Heidelberg, 2011, pp. 503-532. doi:10.1007/978-3-642-01169-6_21.

URL https://doi.org/10.1007/978-3-642-01169-6_21 
[6] L. F. M. da Silva, R. D. Adams, B. R. K. Blackman, L. Goglio, M. Peroni, C. Sato, K. Dilger, M. Frauenhofer, S. Kreling, Higher Rate and Impact Tests, John Wiley \& Sons, Ltd, 2012, Ch. 4, pp. 273-317. arXiv:https://onlinelibrary.wiley.com/doi/pdf/10.1002/9783527647026.ch4, doi:10.1002/9783527647026.ch4.

URL https : //onlinelibrary .wiley.com/doi/abs/10.1002/9783527647026.ch4

[7] N. Cocheteau, A. Maurel-Pantel, F. Lebon, I. Rosu, E. Prieto, S. AitZaid, I. Savin De Larclause, Y. Salaun, Process parameters influence on mechanical strength of direct bonded surfaces for both materials: silica and zerodur@ glasses, Journal of Adhesion Science and Technology 28 (10) (2014) 915-934. doi:10.1080/01694243.2013.876138.

URL http: //www . tandf online.com/doi/abs/10 .1080/01694243.2013.876138

[8] N. Cocheteau, A. Maurel-Pantel, F. Lebon, F. Mazerolle, I. Rosu, S. Ait-Zaid, I. S. D. Larclause, Influence of roughness on me-

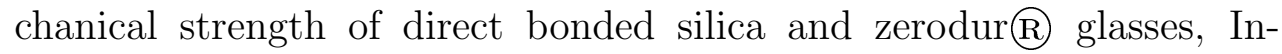
ternational Journal of Adhesion and Adhesives 68 (2016) 87-94. doi:10.1016/j.ijadhadh.2016.02.006.

[9] Q. Bui, A. Maurel-Pantel, F. Mazerolle, C. Hochard, The flexible initiation test (FIT): A new experimental test to characterize fracture initiation in mode 1 at the free edge of bonded assemblies, International Journal of Adhesion and Adhesives 84 (2018) 291-300. doi:10.1016/j.ijadhadh.2018.02.037.

[10] R. Adams, J. Harris, A critical assessment of the block impact test for 
measuring the impact strength of adhesive bonds, International Journal of Adhesion and Adhesives 16 (2) (1996) 61-71.

[11] B. Valès, S. Marguet, R. Créac'hcadec, L. Sohier, J.-F. Ferrero, P. Navarro, Experimental \& numerical study of the Tensile/Compression-Shear Arcan test under dynamic loading, International Journal of Adhesion and Adhesives 78 (2017) 135-147. doi:10.1016/j.ijadhadh.2017.06.010.

URL http: //linkinghub.elsevier .com/retrieve/pii/S0143749617301124

[12] B. Valès, S. Marguet, R. Créac'hcadec, L. Sohier, J.-F. Ferrero, P. Navarro, An experimental method dedicated to the dynamic characterization of structural adhesives under drop weight conditions, International Journal of Adhesion and Adhesives 90 (2019) 106-125.

[13] L. Arcan, M. Arcan, I. M. Daniel, Sem fractography of pure and mixedmode interlaminar fractures in graphite/epoxy composites, in: Fractography of Modern Engineering Materials: Composites and Metals, ASTM International, 1987.

[14] J. Cognard, P. Davies, B. Gineste, L. Sohier, Development of an improved adhesive test method for composite assembly design, Composites Science and Technology 65 (3-4) (2005) 359-368. doi:10.1016/j.compscitech.2004.09.008.

URL http://linkinghub.elsevier.com/retrieve/pii/S0266353804002131

[15] J.P. Brossard, Choc sans frottement entre solides, Tech. rep., INSA de Lyon (1994). 
[16] J. M. Whitney, R. J. Nuismer, Stress fracture criteria for laminated composites containing stress concentrations, Journal of composite materials 8 (3) (1974) 253-265.

URL http://jcm.sagepub.com/content/8/3/253. short

[17] P. Bailly, Materials and structures under Shock and Impact, John Wiley \& Sons, 2013. 